Portland State University

PDXScholar

\title{
The Impact of the Multinational Corporations on Leading Issues and Policy Making in Less Developed Countries. (A Case Study on Kenya)
}

Wamukota Francis W. Wambalaba Portland State University

Follow this and additional works at: https://pdxscholar.library.pdx.edu/open_access_etds

Part of the African Studies Commons, Macroeconomics Commons, and the Public Affairs, Public Policy and Public Administration Commons Let us know how access to this document benefits you.

\section{Recommended Citation}

Wambalaba, Wamukota Francis W., "The Impact of the Multinational Corporations on Leading Issues and Policy Making in Less Developed Countries. (A Case Study on Kenya)" (1985). Dissertations and Theses. Paper 3563.

https://doi.org/10.15760/etd.5445

This Thesis is brought to you for free and open access. It has been accepted for inclusion in Dissertations and Theses by an authorized administrator of PDXScholar. Please contact us if we can make this document more accessible: pdxscholar@pdx.edu. 
AN ABSTRACT OF THE THESIS OF Wamukota Francis W. Wambalaba for the Master of science in Economics presented April 8 , 1985

Title: The Impact of the Multinational Corporations on Leading Issues and Policy Making in Less Developed Countries. (A Case study on kenya)

APPROVED BY MEMBERS OF THE THESIS COMMITTEE:
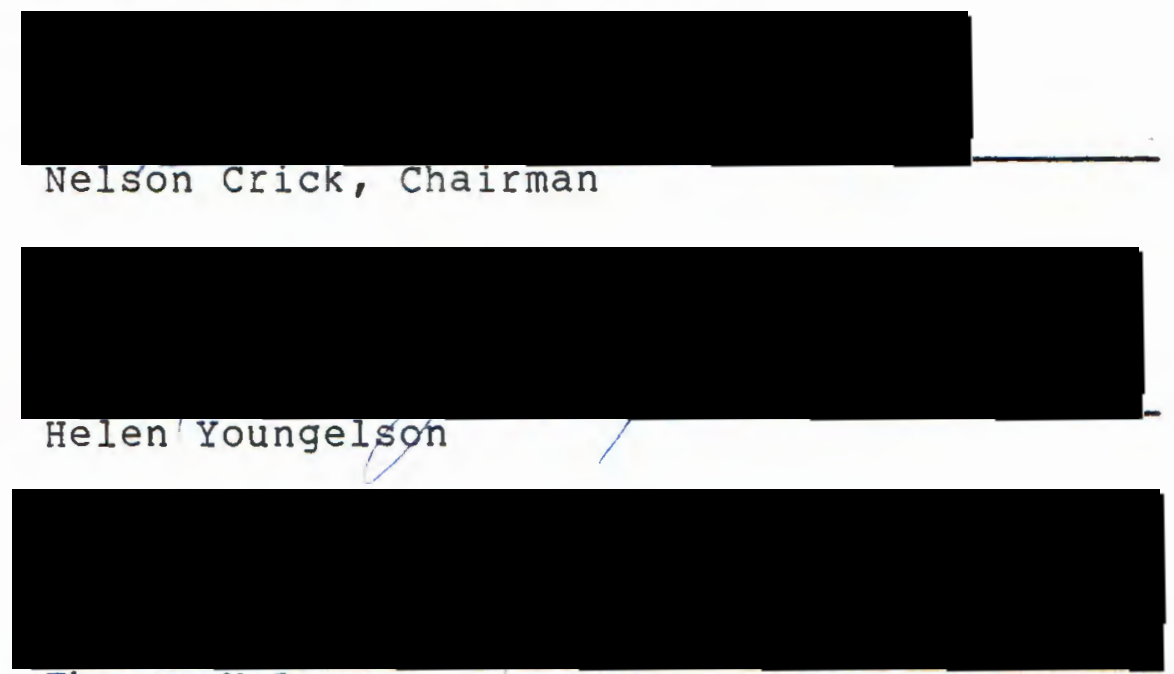

Thomas McLean

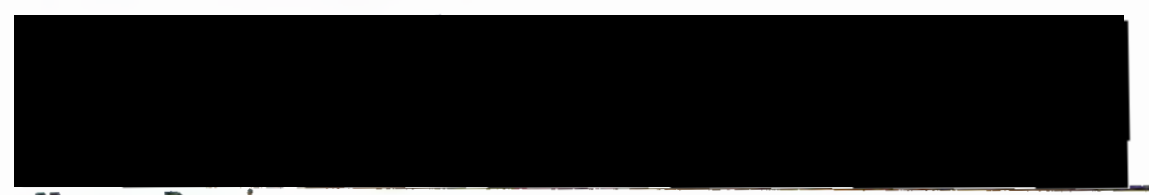

Veer Beri

The era of Multinational Corporations (MNCs) is so significant in the development of the Less Developed Countries (LDCS) as was the era of the Industrial Revolution in the development of the now More Developed Countries 
(MDCS). It could be referred to as one of the major economic frontiers in the LDCs as is the computer frontier in the MDCs now. Naturally therefore, there are problems of distrust, fear of eventual crisis, uncertainty of the correct path and a pain in policy making. Coupled with the North/South delicate relationship, the MNC's (which mostly comes from the North) acceptability in LDCs (which are in the south) is of mixed feelings.

In this paper therefore we shall explore some of the problems affecting the MNC/LDC relationship. Thus, among the questions to ponder on are what has been the impact, is it harmful or beneficial, do all MNCs have the same impact and how does each party interpret each impact? These questions often end up in accusations between MNCs and LDCs in general without devouring each other. But not without a loss of resources especially time and extra costs involved in speculations on each other as well as cushioning of uncertain events that one party suspects of the other.

These issues will be studied with particular reference to Renya's economic development. We will want to know if the MNC's impact (if we are objective) on kenya is contributory to the economic development. To do this, we will need to know the overall performance of the kenyan economy relative to its close neighbors, i.e., Tanzania and Uganda. This will be done in the first chapter of the paper. Then we shall need to observe closely the operation of MNCs in 
the Kenyan industrial sector where they are dominant. This way, we can be able to weigh the proportion of the impact relative to the percentage of the economy that MNC's control. With such a background, we can be able to isolate particular important issues such as technological impact, urbanization impact, the impact on employment, education, politics and other related scenarios. Thus, what issues are involved from the point of view of both parties?

In order to objectively analyze these issues, specific evidences are searched for. These evidences, positive and negative effects, are put on balance as a means to help the Einal analysis on how to improve relationship between MNCs and LDCs. Thus, Chapter III will deal with labor related issues, Chapter IV will deal with rural issues and Chapter $V$ deals with ideological issues. All these issues lead to a policy statement and conclusion in Chapter VI.

Since MNCs and LDCs have fought without actually divorcing each other, the interpretation is that the necessity of coexistence of these parties is higher than their differences. There should be more gains to both than there are losses. Implicit therefore is that distribution of the gains is the problem. In any case, therefore, our view will be on how to patch up this problem, but not to show who is wrong. This view is amplified in the policy statements whereby we shall suggest the criteria for handling 
and evaluating the problems. From these criteria, probable policies are suggested.

Due to the context of the paper (analysis of MNC impact on Kenya) we will not be able to dwell with policies or criteria that MNCs should try. It therefore seems onesided but the theme is the same -- towards coexistence. We will also not be able to explore most of the other problems affecting underdevelopment such as population, climate, health, etc., because the MNCs relative impact on them is not very elaborate. Time and space also limit the exploration of other significant issues. However, those issues used here were seen as very vital especially as concerns the Kenyan position. In sum therefore, this paper presents the MNCS impact in LDCs with a case study on Kenya but does not intend to show these problems as being common to all LDCs nor would the suggested policies be recommended for all LDCs. However, the overall theme should be representative of issues affecting all LDCs. 
THE IMPACT OF THE MULTINATIONAL CORPORATIONS ON LEADING ISSUES AND POLICY MAKING IN LESS DEVELOPED COUNTRIES (A Case study on Kenya)

by

WAMUKOTA FRANCIS W. WAMBALABA

A thesis submitted in partial fulfillment of the requirements for the degree of

MASTER OF SCIENCE

of ECONOMICS

PORTLAND STATE UNIVERSITY

1985 
TO THE OFFICE OF GRADUATE STUDIES AND RESEARCH:

The members of the committee approve the thesis of WAMUKOTA FRANCIS W. WAMBALABA presented April 8, 1985.

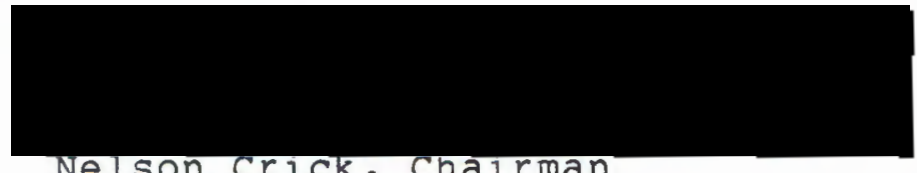

Nelson crlck, chalrman

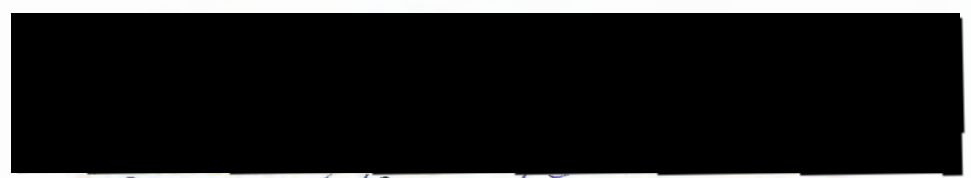

Helen Youngeison

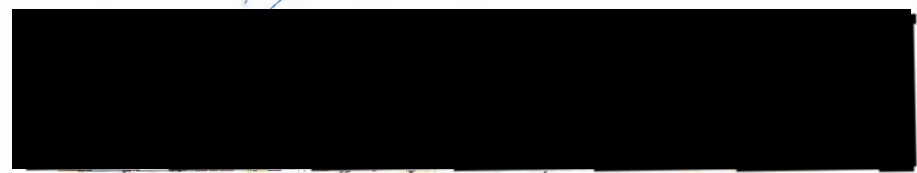

Thomas McLeán

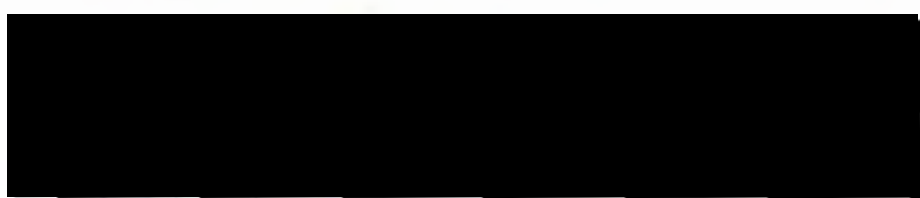

Veer Ber I

APPROVED :

Thomas McLean, Head, Department of Economics 


\section{ACKNOWLEDGMENTS}

In preparation of my thesis I have benefited from the Economics Department faculty of Portland state University, the Weekly Review magazines Business Review section and the International Business studies section of the school of Business at Portland state.

However, without Professor Nelson Crick's advice, guidance and encouragement, I would have accomplished little. Special acknowledgment for the typist, Mary Dozark (PSU, Anthropology) whose patience, advice, analysis and cooperation helped me a great deal. Thanks to members of my committee and the office of Graduate studies for their constructive comments.

My little sister, Mary Nanjala, deserves credit for her psychological support and for this I dedicate to her this thesis. 
TABLE OF CONTENTS

PAGE

ACKNOWLEDGMENTS $\ldots \ldots \ldots \ldots \ldots \ldots \ldots \ldots \ldots$

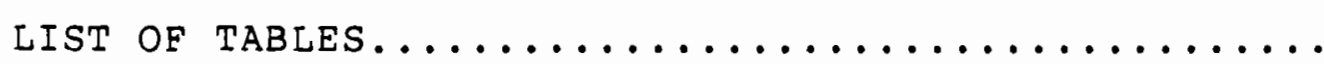

CHAPTER

I

INTRODUCTION .

The Comparative Advantage Approach.....

Similar Factor Approach

Is the Comparative Advantage Approach Invalid?

Overseas Level

A Rejoiner in the Mercantalist Perspective

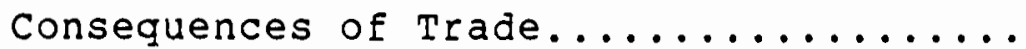

Where is Kenya's Comparative Advantage?

Effects of Trade

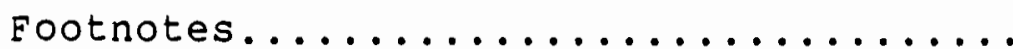

II FOREIGN AID AND INVESTMENTS IN KENYAN

INDUSTRIAL ECONOMY..............

Why MNCs go Abroad............... 19

Empirical studies

Theoretical studies

The Historical structure of LDC's Economies..

Who controls Industry in Kenya........... 25 
The Choice of what to Produce

The Joint Venture system

The Impact of MNCs in Kenya..........
General Effects
Demographic Effects
Education System Effects
Duealistic system Effects
Planning Distortions
Creation of the Elite corrupt
Bougeoisie

MNCs Positive Contributions...........

The Role of MNCs in Economic

Development.................

Policy Remarks..................

The Role of Government

The role of MNCs

Rejoinder

Chapter Conclusion............... 57

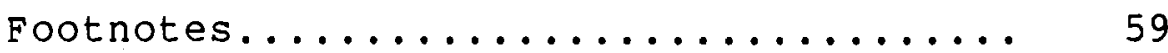

SECTION TWO

SPECIFIC ISSUES.....................

III LABOR RELATED ISSUES.................

Employment Problems................ 74

Income Distribution........... 82

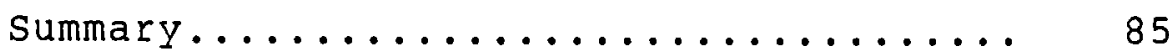

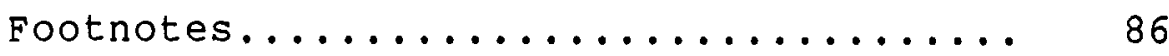


IV ISSUES AFFECTING RURAL DEVELOPMENT.........

Agricultural Transformation

Urbanisation

Rural/Urban Migration

Rural Development

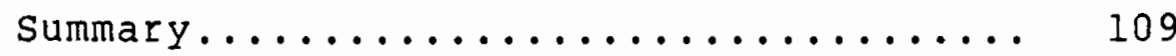

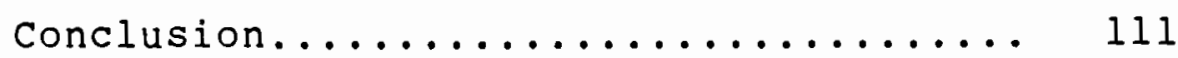

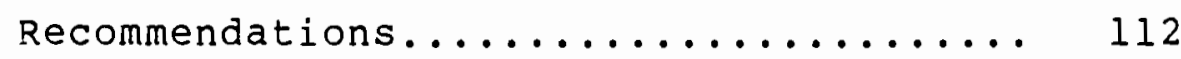

BIBLIOGRAPHY .............................. 122

APPENDIX 1 - Principal Exports from Kenya 1937..... 126

APPENDIX 2 - Kenya's Major Trade Partners......... 127

APPENDIX 3 - Inter-Territorial Trade in East

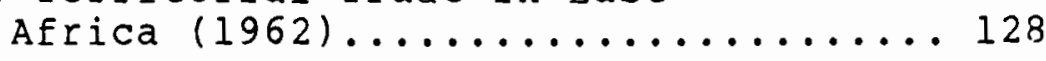

APPENDIX 4 - Visible Balance of Inter-Country Trade.. 129

APPENDIX 5 - Expansion of Inter-Territorial Trade

in E. Africa....................130

APPENDIX 6 - Differential Pricing of Agricultural

Products.................... 131

APPENDIX 7 - Estimated Book Value of Foreign

Investments in Kenya in $1972 \ldots . . .132$

APPENDIX 8 - Main Commodities Exported........... 133

APPENDIX 9 - Value of Major Agricultural Products

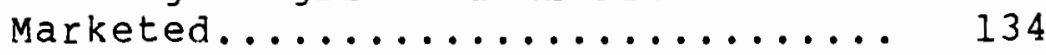

APPENDIX 10- Percentage of Gross Product by

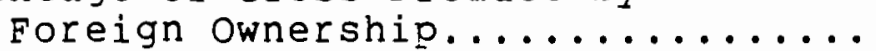


PAGE

APPENDIX 11 - Number of Private Companies Forming in Kenya Between 1955-1973....... 136

APPENDIX 12- Economic Indicators by Province....... 137

APPENDIX 13- Previous Occupation of Market Business-

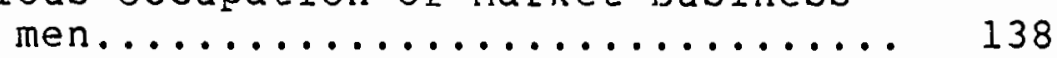

APPENDIX 14- World Trade in Milions (f) Exports

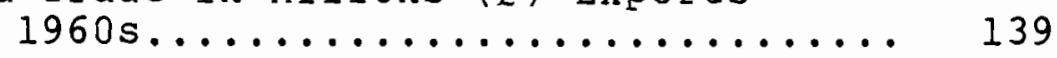

APPENDIX 15- World Trade in Millions (E) Imports

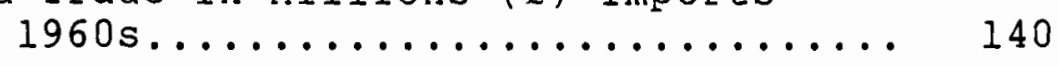

APPENDIX 16- National Income in Millions (E)

Market Prices 1960 s.............. 141

APPENDIX 17- World trade in Milions (Shillings)

Imports $1970 \mathrm{~s} . \ldots \ldots \ldots . \ldots \ldots 142$

APPENDIX 18- World Trade in Millions (Shillings)

Exports $1970 s \ldots \ldots \ldots \ldots . \ldots \ldots 143$

APPENDIX 19- National Income (Millions or Shillings)

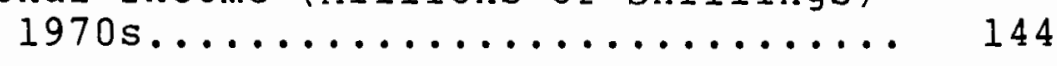




\section{LIST OF TABLES}

TABLE

PAGE

I The GDP and Per Capita Income - East

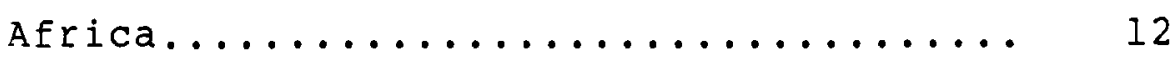

II Availability of skilled Labor............ 27

II Equity Ownership.................... 31

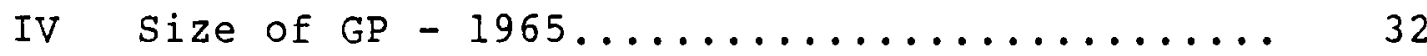

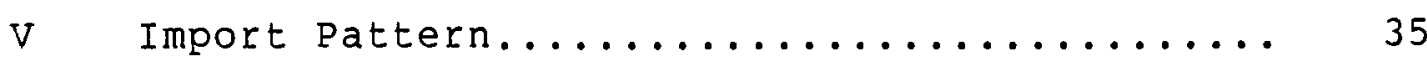

VI Education of Businessmen and the General

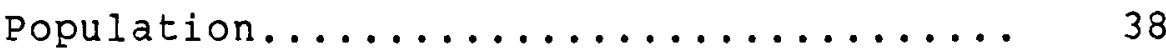

VII Recorded Inflows $(+)$ and Outflows $(-)$ of

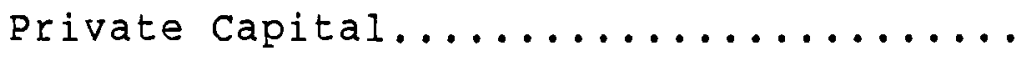


CHAPTER I

INTRODUCTION

This thesis will mainly focus on the impact of the Multinational Corporations in Kenya. However, in order to grasp the effect of this impact, a survey of the national economy will be necessary for acquaintance. This will be in a comparative form to enable a broader perspective of the economy's relative weight and how much of the MNC effects it can handle.

In chapter II, the Industrial base is examined especially as it relates to the MNCs. This is essential as a providing link between the economy's overview and the particular leading economic issues that have had the impact of the MNC.

The later chapters deal with particular issues. Thus Chapter III deals with labor related issues, Chapter IV deals with issues affecting rural areas, Chapter $V$ analyzes the ideological issues and chapter VI is a policy statement together with the conclusion of the thesis.

The major theme would be to show positive effects of most MNCs in Kenya's economic development in the background of alarming complaints against MNCs in Less Developed Countries (LDCS). The aim is to forage for a symbiotic approach that would foster economic growth between these 
two adversaries who by no means can never afford to leave exclusive of each other.

Even though the period of study provides reference from as early as 1930 to 1984, the main focus will concentrate on the period of the 1960s and 1970s. The $1960 \mathrm{~s}$ provide a picture of investment strategies which are reflected in the 1970s' outcomes both in terms of output as well as further restructuring of investment strategies. It's from these counter effects that we shall base our evaluations and recommendations.

The policy statement therefore makes a rejoinder of the issues towards a suggestion of a cohesive strategic economic development.

Due to fewer local authors on the topic, I have used most of the material from foreign authors, government publications and news media literature as well as company publications which all the same represent reliable references. 


\section{THE COMPARATIVE ADVANTAGE APPROACH}

The theory of comparative advantage requires a nation to specialize, produce and export a commodity of which it has the least comparative disadvantage. Based on this theory, East Africa as a region will benefit much more from trade if it specialized in the production of agricultural crops such as tea, coffee, cotton, sisal, etc. In return, it should import capital items from industrial countries.

Some studies have shown this to have been the case in that in 1937, Kenya's exports of the eight top agricultural products accounted for 76.98 of the total exports with coffee, sisal and tea alone accounting for $48.1 \%$ while gold accounted for 10.7\% (see Appendix 1 [Swainson 1980: 46]). 1 And according to the Kenyan Bureau of statistics, agriculture alone accounted for $32.8 \%$ of the Gross Domestic Product (GDP) of the Monetary sector in $1975,30.8 \%$ in 1976 and 29.78 in 1978 while manufacturing accounted for only $12.58,14.18$ and 16.28 respectively. This data is based on the total monetary sector of $76 \%$ in $1975,76.2 \%$ in 1976 and 77.18 in 1978 of the $\mathrm{GDP}^{2}$ (A Business International Report 1980: 26). This reflection implies the emphasis of agriculture in East Africa.

These data are also supported by the "Business International S.A" research team which found out that Kenya's 
imports "consist of mainly industrial machinery, crude petroleum and motor vehicles followed by iron and steel, agricultural machinery, pharmaceuticals", etc., while its exports " lean heavily to coffee, tea and petroleum products" $^{3}$ (A Business International Report 1980: 27). To further rationalize this comparative advantage approach is the fact pointed out by the same research that kenya's trade partners were mainly the industrialized countries. Thus, between them, Germany and the U.K. imported 498 of Kenya's exports while 518 of its imports came from European Economic Community (E.E.C.) countries. According to the 1978 U.S. Embassy report in Nairobi, the major trade partners ranked according to importance were U.K., Germany, Japan, Iran, U.S., France and Italy for imports while the U.K., Germany, Netherlands, U.S., Zambia and Japan for exports $^{4}$ (see Appendix 2) (A Business International Report 1980: 29]), i.e., mostly industrialized countries.

In summary therefore, based on the 1937 and the recent 1978 data, the evidence so far suggests that the comparative advantage approach holds for East African overseas trade.

\section{Similar Factor Approach}

The reliability of the Comparative Advantage Approach is still far from perfection, however. One study that weighs heavily against this approach has indicated that 
trade, on the contrary, occurs between countries with similar income and technology. Thus, because countries export goods that have already been successful in the local markets and because income determines the type of a commodity to consume, there will be trade within these countries. Implicitly therefore, there should be more trade within East Africa than it is with overseas partners. For example, not only are most of the manufactured goods from kenya sold into Uganda and Tanzania and vice versa, but also tea which is grown in each of the three countries has been found to be traded within the East African Community (EAC) probably based on transportation costs, product differentiation or due to speculative motives.

Based on the above analysis, another factor to think of is that even the industrial development that there is, is emphasized on the basis of import substitution rather than export oriented (except for exports within E.A.C.). 5 (A Business International Report 1980: 53). For example, in Kenya the government has not only given a lot of protection to foreign investors against competition but also the output from these investments is sold within the E.A.C. ${ }^{6}$ (Swainson 1980: 232). The implication of these points is that even the kind of products produced by foreign firms in East Africa are only meant for trade within the E.A.C. (i.e., import substitution). Otherwise they would have 
found their way out to some place elsewhere or even not been manufactured in E. Africa in the first place.

a) Factor endowment evidence. To further amplify on this issue, note the fact that most of the subsistence economy is within the agricultural sector. We can therefore suggest that Kenya's high percentage in the monetary sector relative to Tanzania and Uganda can account for its being more industrialized. Thus in 1960, Kenya's monetary sector ranged from 77.78 of the economy to 78.78 in 1961 compared to Tanzania's 65.18 to 64.88 and Uganda's 72.78 to 71.28 in the same period ${ }^{7}$ (Leys 1974: 118). On the other hand, the G.D.P. estimates for 1960-63 show that kenya's agriculture and fishing contributed only $22.0 \%$ of G.D.P. while manufacturing contributed 18.28 compared to Tanzania's 39.38 of agriculture and fishing with 14.78 manufacturing while Uganda had $49.8 \%$ agriculture and fishing with only $10.9 \%$ in manufacturing ${ }^{8}$ (Leys \& Robson 1965: 227). And the last indicator we want to use to show Kenya's endowment advantage in manufacturing is probably its high rate of capital formation, i.e., 37.98 compared to $23.9 \%$ for Tanzania and $16.7 \%$ for Uganda ${ }^{9}$ (Leys \& Robson 1965: 227).

b) The corresponding trade pattern. Now that we have found Kenya's data to show a resource endowment in manufacturing over the rest of E. Africa, the comparative theory suggests that kenya should export manufactured 
products and import agricultural products within the community. The former (exporting manufactured goods) has held while the latter (importing agricultural goods) has not. According to the Annual Trade Report for Kenya, Uganda and Tanzania, the value of food imported in 1962 from Kenya to both Uganda and Tanzania netted $59 \%$ of the community's food output with $26 \%$ exported to Uganda while $33 \%$ to Tanzania. In return, Uganda's net of 28.38 was exported, 25.78 to Kenya and only $2.6 \%$ to Tanzania while Tanzania's net of 12.98 was exported, 10.98 to Kenya and $2 \%$ to Uganda10 (Leys \& Robson 1965: 228). As shown in Appendix 3, Kenya exported more of both products (agricultural and manufactured) than it imported ${ }^{11}$ (Swainson 1980: 223-235). This trade pattern runs contrary to the suggestion that a country usually specializes in a commodity of which it has the least comparative disadvantage given the above endowment evidence.

\section{Overseas Level}

The above studies on inter-territorial trade might be due to some interference into the market system. Governments, as we shall see, have often times intervened in market resource allocation for political and social reasons. The other reason why Kenya has not specialized in manufacturing completely is economic, i.e., overseas trade. Thus, Kenya does not only have the least comparative disadvantage 
in agriculture relative to its major overseas trade partners (Britain and Germany) but in fact, all East African nations tend to trade more with other countries outside the community than within.

For example, Kenya's import value from overseas was 90.48 and only 9.68 from East Africa, Tanzania had 77.38 from overseas and 22.78 from East Africa while Uganda had 77.48 from overseas compared to $22.6 \%$ from East Africa. The exports to overseas on the other hand accounted for 72.18 from Kenya, $95.7 \%$ from Uganda and 83.98 from Tanzania compared to exports within the community of 27.98 from Kenya, 4.38 from Uganda and 16.18 from Tanzania ${ }^{12}$ (Leys \& Robson 1965: 229). This picture of overseas/inter-territorial trade pattern indicates that the comparative theory is not invalid so far.

\section{A Rejoiner in the Mercantalist Perspective}

The theory of comparative advantage was originally meant to correct the mercantalist view of trade whereby gains to one country represented losses to the other. However, based on the analysis and interpretations of the balance of payments, it is in my view that the mercantalist perspective still has some dominance. Thus, even if both countries gain from trade, the terms of trade and their effects have been given a stronger attention in the economic and political arena than absolute gains in themselves. In 
this case, gains are seen as being absolute whereas terms of trade are relative. Given that countries usually determine their gains according to how much better they have performed in comparison to other countries (e.g., the highest GNP, highest per capita income, highest standards of living, etc.) rather than how they did on overall, the mercantalist interpretation remains important. It is with this view that we analyze the consequences of trade in East Africa. 


\section{CONSEQUENCES OF TRADE}

The economics theory has shown and pedagogically proved that there are benefits from trade. Theories too, have pointed out the limits of these benefits. Implicit in these theories is the fact that assumptions behind every theory must hold. However, some assumptions and some neglected factors inight be so strong as to invalidate a theory. Hence, the better measurement is the empirical evidence.

For example, one of the factors neglected by the comparative advantage approach is the feelings on the rationality of distributing trade benefits. Whereas the E. African inter-territorial trade has contributed to a sustained economy within the EAC in general, the comparative advantage policy in particular has led to the enriching of the Kenyan nation relative to its partners. Thus, as we have statistically seen, Kenya has been the major producer of both agricultural and industrial products. This is mainly because of the centripetal economic force in the form of Economies of scale. The dictates of this force has been the establishment of an imperfect market in which the theory of comparative advantage has therefore failed to hold. Thus, the original comparative advantage has been modified into what I would call an "advanced absolute 
advantage" (i.e., where the price ratio of products exchange makes one country to have an absolute advantage in all commodities) and therefore reaching to a point where trade is exploitative (i.e., there are the same "N" units of benefits but all in favor of one partner).

These facts are reflected in the balance of trade within the E.A.C. countries as shown in Appendix $4^{13}$ (Zwanenberg 1975: 244). According to this data, over a range of five years Kenya had a positive balance of payments all the way while both Uganda and Tanzania simultaneously showed negative balances. This is consistent with historical trends which show the "percentage of total value of East African interterritorial exports" as they correlate with the intensification of trade. Thus, noting the fact that after World War II, Britain incorporated Tanzania to form the Imperial British East African Company (IBEAC), and therefore the beginning of the common Market, it is striking to notice that Kenya's percentage value from trade was 36.28 in 1945 , Uganda had 418 and Tanzania had 22.88. In 1951, Kenya commanded $50.8 \%$ of the value, Uganda got 33.58 and Tanzania survived with 15.78. By 1966, Kenya had the leading of 65.78 of the value while uganda obtained 23.78 and Tanzania made only $10.68^{14}$ (Zwanenberg 1975: 242).

The implication of this data correlating with the formation of the Common Market is that the more open the 
market became, the more one nation (Kenya) gained while others (Uganda and Tanzania) lost. Consequently, Kenya has obtained the highest GDP and per capita income compared to its partners as the table below shows for the 1976 study ${ }^{15}$ (Killick 1976: 57).

Related to this is the data which shows "expansion of inter-territorial trade in East Africa between 1944 and 1966 which is shown in Appendix 5 (Zwanenberg 1975: 243). 16 As we have already noted that there is no question about occurrence of benefits but a question about distribution. This data shows that all countries have been expanding. However, Kenya expanded from Kfl.09 millions in 1944 to $\mathrm{K} 28.9$ millions in

The GDP and Per Capita Income - East Africa

Country

Kenya

Uganda

Tanzania

Per Capital Income (Shs)

39

31

30
934

870

637

SOURCE: Tony Killick, University of Nairobi, "Past and Future Research on the East African Economies", Eastern Africa Economic Review, Vol. 8, \#1, December 1976.

1966 compared to Uganda which started at a high of $\mathrm{K} 1.98$ millions in 1944 to K 10.45 millions in 1966 while Tanzania grew from K .66 millions to $K 4.65$ millions in the same 
period. The evidence so far doesn't deny the benefits predicted by the comparative theory but questions the usefulness of those benefits. If trade is beneficial, it should encourage both partners to trade rather than discourage them. In this case for East Africa, we have found that the closer together was the idea of a Common Market, the more discouraging were the results.

\section{Where is Kenya's Comparative Advantage?}

Given the fact that Kenya had advantages in both agricultural and industrial goods, we will use kenya to represent the trend of trade between East Africa and the rest of the world as well as trends within the community simultaneously. As already noted, trade with the rest of the world has mainly involved agricultural exports and industrial imports. The major trading partner is Britain which is its former colonial power. For example, according to the data released in November of 1983 by the Kenya Tea Development Authority (KTDA), 508 of tea imported into Britain is from Kenya. And while Kenya commands $9.8 \%$ of the total world tea export, it ranks third to India and srilanka for total world tea output ${ }^{17}$ (Vernon 1981: 94).

However, Kenya's main export is not tea but coffee, i.e., in 1970 coffee accounted for $31.1 \%$ of the total exports, tea was $17.7 \%$, petroleum products $11.4 \%$, meat $4 \%$, pyrethrum $3 z$, sodium carbonate. 28 , etc. In terms of GDP, 
agriculture accounted for $14.26 \%$, manufacturing and repairing $10.98 \%$, transport and retail $9.94 \%$, etc. 18 on the other hand, the growth rate was 15.5 in in construction, 10.98 in banking and insurance compared to $7.7 \%$ in manufacturing and only 4.98 in agriculture (Leys 1974: 276278).

The significance of this data is to show the importance of Kenya's agriculture in trade with overseas countries and therefore implying that kenya is more of an agricultural than industrial country. In return, Kenya and other community members import industrial and machinery products from overseas.

Indeed, Kenya imports more products from overseas than from the community, i.e., K£41.5 millions from the U.K., K£24.5 millions from western Europe and only K£15.9 millions from the EAC. On the contrary, Kenya exports more products to the EAC than overseas, i.e., KE31.4 millions to the EAC, KEl4.8 millions to the U.K. and KEl3.3 millions to western Europe (a phenomena that reveals some relative bargaining powers). This fact indicates some elements of comparative advantage in that most of Kenya's imports are from industrialized countries on which it capitalizes by dominating the EAC markets. 
Effects of Trade

As we have previously seen, trade has affected factor allocation, distribution of benefits and general growth. In terms of resource allocation, Kenya has come out with a dual economy producing agricultural products for overseas trade while manufactured goods for the community. The latter has encouraged foreign investments in Kenya. For example, even by 1965 when the community was still young, U.S. investments had already amounted to $\$ 90$ millions in Kenya (Blood 1966: 84).19

In terms of distribution, it is said by many economists that commodity and factor exchange is beneficial to both partners. Paul samuelson has focused on what he calls the "positive effect of a transfer on the terms of trade" and "the welfare effect of transfer on the donor and the recipient", 20 (Bhagwati 1983: 606) i.e., exchange is beneficial. This exchange not only applies to commodities but also to factors such as technical assistance, general labor, capital, etc. According to F.L.R. Batiz of the University of Chicago, immigration affects the price competitiveness of industries it helps to expand 21 (Bartiz 1983: 184). Thus, in the case of East Africa, the supply of technocratic labor helps to push down the prices of the commodities produced by that labor in order to be competitive on world markets. 
However, this distribution also has negative effects especially on balance of payments (to use our advanced mercantalist thinking). As we saw earlier, kenya had a surplus while Tanzania and Uganda maintained deficits. From the previous statistics we have also noticed that Kenya imported more from overseas than it exported. The consequence relationship that is established based on comparative advantage theory therefore becomes that of the weak and the strong thereby affecting the bargaining power and terms of trade. These terms are fixed by the relative bargaining power of the partners through price differentials in favor of the powerful ones. For example, in 1962, most of Kenya's exports overseas were priced below the prices of those goods exported to the community (see Appendix 6) ${ }^{22}$ (Leys \& Robson 1965: 84). This is enhanced by the accumulation of resources through demand and supply forces that favor Kenya. In Marxian terms, a capitalist drive to exploit which Lenin refers to as imperialism. According to Lenin, this exploitation is the result of the "monopoly stage of capitalism" as opposed to the "competitive stage of capitalism" in which there is no strong/weak relationship. 23 


\section{FOOTNOTES}

${ }^{1}$ swainson, N., "The state and Economy in Kenya", The Development of Corporate Capitalism in Kenya 1918-1977. (University of California Press 1980), p. 46.

${ }^{2}$ Economic survey 1979. Business International Research Report, p. 26.

3

Ibid, p.27.

4 Ibid, p. 29 .

5 Ibid, p. 53.

"Swainson, N., "The state and Economy in Kenya", The Development of Corporate Capitalism in Kenya 1918-1977. (University of California Press 1980), p. 232 .

${ }^{7}$ Leys, Collin, "Foreign Capital". Underdevelopment in Kenya, (University of California Press 1974), p. 118 .

${ }^{8}$ Leys, C. and Robson, P. "Appendix". Federation in East Africa (Oxford University Press 1965), p. 227.

9 Ibid, p. 227.

10 Ibid, p. 228.

11 Ibid, pp. 233-235.

12 Ibid, p. 229.

${ }^{13}$ Zwanenberg, R. M. A. and King, A., "East African and Economic Federation", An Economic History of Kenya and Uganda, 1800-1970 (Humanities Press 1975), p. 244.

14 Ibid, p. 242.

15 Killick, T, "Past and Future Research on the East African Economies". Eastern African Economic Review, December 1976, Volume 8 , Number 1, p. 57 .

${ }^{16}$ Zwanenberg, R. M. A. and King, A., "East African and Economic Federation", An Economic History of Kenya and Uganda, 1800-1970 (Humanities Press 1975), p. 243. 
${ }^{17}$ Vernon, R. and Wells, L. T., (A company report release) Weekly Review Publication, Kenya (Nov. II, 1983), p. 26 .

18 Leys, Collin, "Foreign Capital". Underdevelopment in Kenya, (University of California Press 1974), p. 276-278.

19 Blood, W. J., "Business Conditions in East Africa". Management Looks at Africa, (Library of Congress Card Number 66-24179), 1966, p. 84.

20 Bhagwati, J. N., Brecher, R. A. and Hatla, T., "The Generalized Theory of Transfers and Welfare: Bilateral Transfers in a Multilateral World". The American Economic Review, september 1983, p. 606.

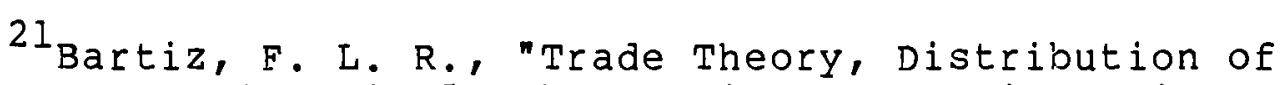
Income and Immigration", The American Economic Review, May 1983, p. 184 .

22 Leys, C. and Robson, P. "Appendix". Federation in East Africa (Oxford University Press 1965), p. 84.

${ }^{23}$ Gurley, J. G., "The Triumph of Capitalism". Challengers of Capitalism (W. W. Norton \& Co. 1979), p. 79. 
CHAPTER II

FOREIGN AID AND INVESTMENTS IN KENYAN INDUSTRIAL ECONOMY

The previous chapter dealt with the whole Kenyan economy and where its strength lies. This chapter focuses mainly on the industrial economy of kenya that is more related to the MNC operations. Whereas the previous chapter portrayed a strong economy in charge of its own destiny with few exceptions, this chapter takes a skeptical view in terms of economic implications of MNC operations in Kenya especially in social and political spheres.

The chapter runs through topics such as why MNCs go abroad, LDS economic structures, who controls Kenya's economy, impact of MNCs and possible policies in such situations. It is with this background together with the previous chapter that a diversified picture of various questionable issues of significance will be brought to light. This background also shades the image of how complicated it can be to deal with most problems related to international economic operations. The situation is even worse when evaluating the LDC-MDC relationships as they are linked by the MNCs. 
WHY MNCS GO ABROAD

\section{Empirical studies}

The Multinational Corporations have been theoretically and empirically determined to go abroad based on a variety of reasons. On one hand, this may be induced from within the parent company such as the desire to make profits, market share, diversity, use their competence among the economic reasons, while the other reasons colld be political such as strategic or ideological, historical or geographical. On the other hand, the inducement may come from the host country which may desire to promote employment for purposes of obtaining revenues, technology, improving exchange reserves or politically such as to maintain its power.

According to Eiteman and Stonehill (1982:4) based on the rate of return, the company will want to translate product market imperfections into market opportunities. And only large firms (operating international), are better able to exploit such competitive facts as economies of scale, managerial and technological expertise, financial strength, etc. These large firms are also said to have an advantage of an organized internal information network that can help identify suitable areas of operation. Caves (1982:161), however has not been able to confirm this view which he. 
refers to as arbitrage of capital. Some studies show that in this case, the U.S. should have more foreign investments from abroad than its firms have abroad.

Studies on Kenya emphasize other factors more than the arbitrage motive. Indeed, as we shall see later, the historical and geographic facts have been more influential. Historically, most of the multinational corporations are from Britain as Appendix 7 shows, i.e., $67 \%$ of the book value of foreign investments in kenya were from Britain in 1972. For example, $50 \%$ of banking business was owned by two British firms, 80\% of mineral output, (Langdon 1981:31) and $23.5 \%$ of tea production (Leys 1974:118). This was due to the colonial ties after Kenya obtained its independence from Britain in 1963. Caves has shown that, according to Nankani (1979:Chapter 3), foreign investments are enlarged between LDCs and their former colonial powers not only due to political protection and lower transaction costs but also because their termination posed a threat to the industrial nation's remaining exports to her former colonies. His argument is based on the tariffs that the newly independent countries would install (Caves 1982: 58).

In the case of kenya, this can also be evidenced by the previous large firms that had been established before independence. These firms helped to attract new firms especially when they were not politically affected after independence. This assurance of political stability has 
been theorized by Nehrt (1970) in his book as the Model of Political climate for private investments. In his theory, three variables identified are the policy statements of political leaders and the government such as assuring foreign firms operations, actions of the government such as nationalization, appropriations or passing investment codes, selling, public companies to private firms, etc., and lastly the historical context based on its previous actions and stability. Other theories such as the H-W-M political system stability index (Eiteman 1982:306) use the quantitative method, to determine the propensity of a country to expropriate foreign firms.

On the geographical basis, some of the multinational firms have located in Kenya just because they would have access to the Mombasa harbor or because of the hydroelectric power generated by the Nile. As for the Kenyan Multinational corporations, their location has been based on the distances involved with the countries in which they operate. For example, the Kenya National Trading Company (KENATCO) operations in Jganda, Tanzania, Zambia, Congo, Ruanda and Malawi is based on the geographical closeness that enables direct road communication links.

\section{Theoretical studies}

The major categories that have been classified by Caves (1982: Chapter 1) are those of horizontal, vertical and 
diversified types of MNCs. In using this theory, caves enumerated a variety of reasons why the multinational firms are in existence in the first place. However, common in all of them is the element of transactional costs. These are said to determine a firm's entry into the market or not. Thus, if a firm has an intangible asset that is firm specific such as a proprietary process, the information system, managerial skills, etc., it would prefer to make Direct Foreign Investment (DFI) than try to market that intangible asset at arms length transaction.

Several problems are encountered in this particular firm's approach to FDI because this involves transfer pricing on factors that are not easy to determine the price. The host country will find it difficult to compare prices since there is no any other point of reference while the MNC will find problems of justifying the price it is charging. 
THE HISTORICAL STRUCTURE OF LDC'S ECONOMIES

The Third World countries are mainly characterized by their young economic structures. The structures are stratified in a way that there is very little surplus to be reinvested to generate economic growth. We can compare this situation with Rostow's explanation of the "Precondition to Take off stage". Thus, what is most needed is to break through what Gunner Myrdal has called the Cumulative Causation popularly known by economists as the vicious circle of poverty.

In Kenya, this situation is evidenced by the fast growing population that consumes any extra surplus from production. ${ }^{1}$ Consequently, if Kenya had to break through its vicious circle, it needed an outside emancipating force. This force has inevitably been the Multinational Corporation (MNC). With its negative and positive effects, the MNC has played a significant role in Kenya's socio-economic structure that needs a very close examination. To examine it we divide these effects into those of wholly owned operations or joint ventures and those in which the MNCs are not involved in or have let their hands off. 


\section{WHO CONTROLS INDUSTRY IN KENYA?}

Kenya has a large portion of its economy run by the MNCs. Thus by 1972, the MNCs investments in Kenya were valued at $\mathrm{k} 130$ millions, i.e., over $2080 \mathrm{f}$ the country's Gross National product (GNP) with a net private long term capital inflows of over Kf77 million in the period 19671972 which makes an average of $10 \%$ yearly total capital formation (Langdon, 1981:31). Indeed, in 1972, 508 of the banking business was owned by two British banks, and $80 \%$ of the mineral output was handled by the British owned Imperial Chemical Industries. One survey also indicates that $32 \%$ of wholesale and retail trade employment was accounted to only nine MNC subsidiaries which in fact make up only half of the foreign firms active in this sector (Langdon, $1981: 311$.

In agriculture as well, the MNC's have a large stake, i.e., the British owned Broke Bond Liebig alone produced $23.5 \%$ of Kenya's tea in $1972 .^{2}$ In commerce and industry, some studies have even shown that between 1964 and 1970, $50 \%$ increase of output and $100 \%$ increase in the annual level of investments was foreign owned and controlled (Leys 1975: 118). In all, Kenya's economy between 1965 and 1972 was largely foreign controlled, i.e., equity capital held by companies in Kenya amounted to $64 \%$ foreign owned, $2 \%$ 
owned by other East African countries and only $35 \%$ owned by Kenyan companies (Swainson, 1980:239).

This large foreign controlled sector was a result of historical trends, i.e., after Independence, the British large agriculture estate firms changed into manufacturing such as did Mitchell Cotts and Mackenzie Dalgety while others like Lonrho, British American Tobacco (BAT) and Brooke Bond Liebig expanded through acquisition (Swainson, 1980:215). As Appendix 7 shows, the dominant MNCs were from the U.K., U.S., Germany, France and Japan in that order of ranking. ${ }^{3}$ According to an East African Investment survey, the equity of foreign firms in Kenya consisted of $71 \%$ dominated in the sterling while only $29 \%$ in the nonsterling in 1968 (Swainson, 1980:216)

This empirical evidence implicates the role of MNCs in Kenya's economic decisions to be so vital and significant. One of the areas that is affected by these economic decisions involve what to produce. The rationale could be based on profit maximization, national development or international resource optimization. Given that profit maxinization carries with it a negative connotation while most nationals doubt the faith of MNCs in national development, the dominant rationale has therefore been that of resource allocation. This rationale can be explained by the choice process of what to produce in any given economy. 
The Choice of what to Produce

One of the basic problems in less developed countries' (LDCS) economic development is the choice of what to produce. Given that other things remain constant, the economic rationale postulates that a country should specialize in the production of the commodity it has the least comparative disadvantage. Hence, the question of what to produce doesn't become a problem. In the case of kenya, it should therefore produce coffee and tea because these products happen to flourish so well in kenya. First, this is because of the prevailing climatic conditions which are suitable for the crops. Secondly, these products need plenty of unskilled labor which is apparently available in kenya as the data below shows from the 1962 census.

\section{Availability of Skilled Labor}

Non-formal with Primary with Secondary Education Education Education

Males over

15 years

$68 \%$

318

18

Males 25-29 years

518

46 号

38

Source: Morris and Somerset, The African Entrepreneur, p. 211.

However, the decision to produce coffee or tea will need further qualifications as we can empirically and theoretically find out. Empirically, Kenya decided to produce 
nore tea and coffee as early as the coming of the British Colonial power. As the British Information services reports, the largest farms of over 2000 acres were "estates growing crops such as tea, wattle or sisal" and that almost 908 of the exports from Kenya were agricultural and also. that "the chief export crops, i.e., tea, coffee, sisal and wattle are grown mainly on plantations by European planters. " 4

For example, current data shows that kenya now ranks third to India and Srilanka for total world tea output (Neekly Review, Nov. 11, 1983:26). However, Kenya's main export is in fact not tea but coffee. Thus, in 1950, coffee accounted for $21 \%$ of exports, in 1960 about 298 and in 1970,318 (Leys, 1975:276).

From this empirical evidence, we can safely say that Kenya has positively responded to the comparative approach solution as to what to produce. However, the consequences so far imply that this was a degenerating solution. Since agricultural production demands more unskilled labor, it is most likely that it will perpetuate illiteracy which is a menace to development.

Agricultural products have also been found to be unstable and therefore adversely affecting the balance of payments. Thus, they are vulnerable to natural calamities, they have low income elasticities, i.e., between 0.3 to 0.5 
(Todaro, 1977:371), very competitive and easily replaced by synthetics.

In the face of such agricultural odds, the LDS's have therefore opted for rapid industrialization as evidenced by the Import substitution and Industrialization (ISI) policy in Latin America (Todaro, 1983 by Werner Baer, p. 27). Given their poor economic position, it is not surprising that their only remedy was to be found in the MNCs. And now that the MNCs dominated this industrial sector and even some large scale agriculture, the LDS economic planners had virtually no powers to direct their economies in their own interest. Hence there grew the need for natives to participate in the economic machinery. Due to high initial costs, it is not surprising that the most welcome option was that of a joint venture. In spite of the ill effects that this option promoted, it can equally be argued that the trend and especially in decision making has been impressive.

\section{The Joint Venture system}

The Joint Venture system in Kenya has been increasing at a significant rate. However, the spread has not been diversified in that only a few lucky individuals have been able to buy stocks. The major shareholder in joint ventures however has been the government itself. Therefore, 
foreign equity will still need more time to be matched by private indigenous ownership.

Initially, foreign equity had been declining slowly as a percentage until 1970 when it started to pick up momentum. According to Herman, on average the citizen's equity in joint ventures amounted to slightly over 98 of the new foreign investments between the years 1964-1970. As we will soon see, most of the changes during these years were political and therefore legislative rather than operational (Leys, 1975:119).

on the other hand, since the 1970s, the economic structure in Kenya has changed rapidly from wholly owned MNCs to Joint Venture basis whereby the government, private citizens and organizations have bought substantial shares of the MNCs. This trend actually, as we have noted above, started as early as under the auspices of the 1964 Foreign Investment Protection Act whereby subsidiaries were required to obtain a Certificate of Approved Enterprise for new operations in Kenya. This was followed by the Immigration Act of 1967 that encouraged kenyanization of most operations especially with the creation of the Industrial and Commercial Development Corporation. Thus, after independence it was felt that the economy was dominated by non-kenyans whose decisions might not be in the interest of Kenyan development. To do so, these statutes encouraged Kenyans to have shares to influence major economic decisions by 
affected enterprises. But, the mortar of drastic changes was reserved for the 1970s (Langdon, 1981 $36)$.

As the table below shows, the trend has been increasing in favor of localizing ownership.

\section{Equity Ownership}

\section{Equity}

Year

1965

1968

1972
Local Percentage

37

36

44
64

63$$
64
$$

54
Foreign Percentage

Source: Swainson, 1980:216.

These drastic changes in the 1970s were significant in the strategic industries and most of them were shares bought by government. For example, between 1968 and 1972, the Building Construction and Electricity sector was reduced from 588 to 198 foreign ownership when the government bought $100 \%$ share capital and management of the East 
African Power and Lighting from a British MNC. In mining and quarrying, foreign equity was reduced from 888 in 1968 to $67 \%$ in 1972 after the purchase of the East African Oil Refineries at Mombasa (Swainson, 1980:217-219). As can be seen from Appendix 10, the foreign equity in the manufacturing sector fell from 718 to 638 while Building and Construction (without electricity) fell from $87 \%$ to $75 \%$ and mining and quarrying from $93 \%$ to $81 \%$.

This same trend of Kenyanization is revealed in Appendix 11 which shows the number of private companies forming in Kenya in 1955 as $70 \%$ by Europeans, 28\% Asians, 98 African and $6 \%$ mixed. Ten years later (1965), the number consisted of $28 \%$ Europeans, $34 \%$ Asian, $25 \%$ African and $12 \%$ mixed. By 1973, the combination was $15 \%$ European, 25\% Asian, 468 African and $15 \%$ mixed.

Another indicator reflecting African expansion into the system is in business partnerships which consisted of 118 African in 1954, ten years later was 548 African and by 1973 constituted $80 \%$. According to Swainson's sample of private firms registering in kenya in 1965, Africans dominated the low income firms while in 1973, they had moved to the middle level and even some were in the 100,000 size range as the table below shows. 


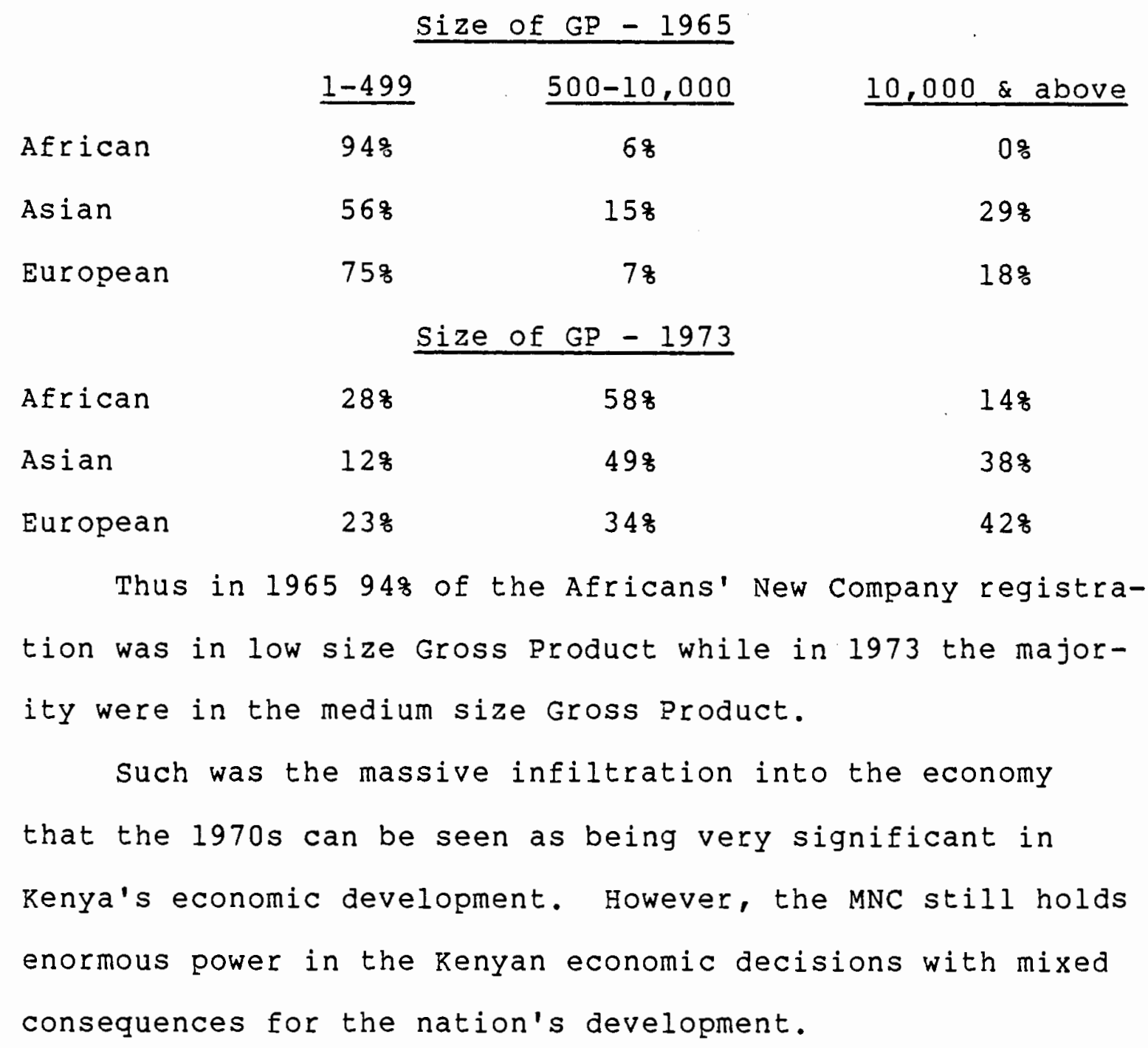


THE IMPACT OF MNCS IN RENYA

The impact which the Multinational corporations have caused on the kenyan social, political, economic and international relations are very significant. Since most of these effects are two-sided with negative and positive effects we shall examine their pros and cons simultaneously. In the preceding sections we shall encounter the term appropriateness. In our case, the term would refer to a technology, expertise, enterprise or influence that is compatible to the economic plan which also states economic policies. Where the planning policy has been said to be inappropriate, such as the education system, I have given a particular criteria of what is appropriate depending on the individual situation.

\section{General Effects}

One effect that the MNCs have brought about is the conspicuous pattern of consumption. This can be partially explained by the trade balance in Appendix 2. According to this data, Kenya's imports from its top seven trading partners between 1976 and 1978 had a percentage increase of more than $25 \%$ while its exports to the six top partners decreased by more than $10 \%$ in the same period. For example, imports from Britain increased by 138.88 while its exports 
to the Netherlands (the sixth of the top importers) declined by 49.28 .

Another supporting explanation can be gathered from the following data.

\section{IMPORT PATTERN MILLIONS OF SHILLINGS}

$$
\underline{1974} \quad \underline{1975} \quad \underline{1976} \quad \underline{1977} \quad \underline{1978}
$$

Consumer goods,

$$
\begin{aligned}
& \text { e.g. , foods, } \\
& \text { beverages, }
\end{aligned}
$$

durables,

semi- \& non-

durable

$\begin{array}{lllll}1214 & 1053.4 & 1230.6 & 1476.3 & 1876.7\end{array}$

Industrial

supplies

$3061.9 \quad 2100.1 \quad 1480.2 \quad 3215.6 \quad 2596.2$

Fuels and

$\begin{array}{llllll}\text { Lubricants } & 1631.3 & 1916.1 & 2077.7 & 2342.9 & 2355.6\end{array}$

Transport

Equipment

$\begin{array}{lllll}887.5 & 935.7 & 882.3 & 15211.1 & 2533.0\end{array}$

Machinery \&

Other Capital

Equipment

860.6

1233.2

1450.4

2060.1

2821.5

SOURCE: Business International, p. 84.

Thus, before 1978, Consumer goods competed effectively with other imports. In fact, in 1974 consumer goods ranked third out of the five large categories of imports, i.e., $40 \%$ of imports consisted of Industrial Supplies, $21 \%$ Fuels and Lubricants, $16 \%$ Consumer Goods, $12 \%$ Transport Equipment and 118 Machinery and other Capital Equipment. 
On the other hand, the Multinationals provided a range of new products that helped to promote Kenya's economy such as nutritious foods, medicine, hygiene products, other useful domestic products, etc. Without proof, here we can attribute to some of the cause for the fast growing population in Kenya to be good nutrition, health care and medicine that have decelerated the death rate.

Also, due to their high economies of scale and efficient technology, the MNCs have encouraged production efficiency in Kenya through effective competition or have helped to check skyrocketing prices. For example, in some commodities, kenya had been found to sell at high prices within East Africa while very cheaply abroad as the table in Appendix 6 shows. The implication is that the market of these products in East Africa had been monopolized by Kenya such that the prices are above world competitive prices. The MNC competitive nature could therefore help to equate the prices.

\section{Demographic Effects}

Another impact has been on rural urban migration especially Nairobi whose population has grown at an unprecedented alarming rate. A study by Langdon has shown that most of the MNCs located their operations in big cities especially Nairobi (Langdon, 1980:93). Ogendo's data is in line with this study in that $52.6 \%$ of industrial operatives 
were located in the two major cities of Nairobi (34.1\%) and Mombasa (18.5\% [Ogendo 1972: 54]).

Worse than this has been a disproportionate distribution of economic amenities in favor of Nairobi Province (see Appendix 12). Thus, in 1974, Nairobi Province recorded wage employment of $79.9 \%$ of the total labor force, recorded twice the earnings per wage worker than the second largest city, had $47.6 \%$ of total hospital beds and absorbed $80.3 \%$ of government expenditures per capita. As a result, $40 \%$ of the industrial workers are employed in these same two cities, i.e., 28.98 in Nairobi and 11.18 in Mombasa (Ogendo, 1972:54). Given this pattern of industrial locations, the consequences have been more labor migrations than equivalent jobs created which is a similar situation to the Todaro rural/urban migration model. This postulates that for every new job created in the cities, more than one immigrant move into the city (Todaro, 1981:239-246).

\section{Education System Effects}

Another problem facing LDCs in the era of MNCs has been the education system. Kenya's education system goes back to the British Colonial school system whose aim was to educate the Kenyan Africans to appreciate and struggle to achieve the British way of life. After Independence, the same system continued but with a slight variation emphasizing the training of Kenyans into the vacant administrative 
positions. In the $1970 \mathrm{~s}$, both systems prevailed but yet with another addition. More administrative technocrats produced than positions trained for are available. This was a blueprint of the MNCs recipe, i.e., the training of the entrepreneur, the accountant, the salesperson, the systems analyst, the independent consultant and a huge army of secretaries who all set the important trends of the economy. These business technocrats have further encouraged education by sponsoring aspiring business people mostly based on the level of education as the table below shows.

Education of Businessmen and the General population 1962 8 of Years of Formal Education None Primary Secondary Males over 15 years 688 318 18 Males 25-29 years 518 468 38

Mkt businessmen $23 \%$ 738 48 ICDC Supported Businessmen 78 688 $25 \%$

Source: Harris and Somerset, p. 211.

Thus, the percentage of males between ages 15 and 24 without formal education is 688 and only 18 with secondary education while those of ages 25-29 were 51\% and 38 respectively. Compare these percentages with businessmen supported by the Industrial Commercial and Development Corporation (ICDC) of $7 \%$ without education and $25 \%$ with secondary 
education. Moreover, a correlational effect of education and business can be made when one compares the $23 \%$ market businessmen without education with 738 with at least some primary education.

Another role that education has played in business is that the size of business has been related to the level of education. A study done by Morris and somerset indicates that 408 of the businesses were owned by businessmen with less than four years of formal education, and without an employee while only $25 \%$ had more than six employees. On the other hand, those of more than nine years of education consisted of only 48 without an employee and $13 \%$ with more than six employees. The ICDC supported businessmen with less than four years education consisted of only $8 \%$ with over 11 employees while $30 \%$ for those with secondary education.

The consequences have been very reflective of what the business community expected. Only 218 of businessmen with less than four years of education had profits above sh 300 compared to 438 of businessmen with secondary education (Morris and somerset, 1971:212-213).

\section{Dualistic System Effects}

Against these leaps is the reality of the economy. As we have seen, only those privileged with access to formal education have been successful in the business world just 
as the few who got administrative positions succeeded in the previous educational system. The vast majority are doomed including even some with formal education. And among those with access to education, only those previously employed in skilled manual jobs were successful (see Appendix 13). The implications of such a system which renders its victims knowledge which they will never use is very discouraging. All the three systems have focused on exogenous rather than indigenous symbiosis of all factors that will promote development. Thus, whereas the successful few have been able to be integrated into the international business system, the vanquished majority have been subordinated to an internal structure that is expensive and hard to break through. The dualistic nature can be likened to Amin's classification of the center and the periphery, i.e., the few advantaged make up the local center that attracts the flow of wealth from the peripheral while through their international links, they act as the medium of resource transfer from LDCs. Hence there is a need for a structure that can avoid this kind of vagaries of the MNC's era.

\section{Planning Distortions}

Coupled with these bleak chances of success based on education, the consequential unemployment has been the constant feature of technology. And indeed, the most 
significant impact of the MNCs has been their sophisticated technology too exotic for appropriate utilization. often times it has led to disastrous results due to lack of comprehensive feasibility analysis. For example, in one district, it was hoped that introduction of hybrid dairy cows would not only provide milk for families but would also augment the supplies to the Kenya Creameries corporation (KCC). The corporation loaned the progressive farmers funds to purchase the new breeds. However, since some farmers were skeptical of the new breed, they not only continued to keep their native cows but also refused to fund the cattle dip to be constructed for prevention of the East coast fever from ticks. And since they couldn't use the dip and their cows were immune, the disease was never combatted and within two years there was no surviving landmark of a hybrid cattle except for the huge debts on the backs of progressive farmers.

Another case involved consolidation of land for economic large scale farming. On the slopes of Mt. Elgon small patches of land separated by tufts of grass were sold to large scale progressive farmers who used tractors. Their farming became so massive but without erosion checks that rain and wind took off the fertile top soils. This resulted in very low output per unit of land than before. Worse, some technologies have been imported as a salvaging process when found obsolete in the originating 
country. In such cases, not only have kenyan industrialists been forced to remain behind their counterparts in developed countries but they have also been locked into a technology whose spare parts are hard or economically expensive to find. And not to mention the pollution effect (e.g., the Indian Pan Paper Mills that has polluted and killed all wildife along the third largest river in Kenya and now threatens its mouth - Lake Victoria, the second largest lake in the world).

And lastly, because of their emphasis on mechanization, part of the unemployment problem in kenya can be attributed to these technologies. According to ogendo's study, mechanization has often increased with the size of the firm and that most of the employment was provided by non-mechanized operatives, i.e., 58.1\% (Ogendo, 1972:78). And according to the Industrial Census of 1971, the highest numbers employed were in rolling stock, textiles, and sawn timber while major industrial branches in Kenya are capital intensive and use relatively smaller amounts of labor compared to their output.

Creation of the Elite Corrupt Bourgeoisie

Along with this structural unemployment is the effect on income distribution. The MNC's mechanized efficient production makes it possible for them to pay higher wages than Kenyan average wages. However, the main problem here 
is not based on productivity but on company wage scales. Given that a counterpart manager in the U.S. or U.K. is earning a lucrative wage, the kenyan manager will also demand the same rights from the company. Comparatively, the Kenyan MNC manager will therefore earn more than a fellow Kenyan managing a local equivalent operation. Not only does this disproportionate income distribution enhance the gap between the elite technocrats and therefore discourage local initiative but also it influences political decision making, corruption and poor resource allocation.

In terms of political distortion of the economy, swainson found out that cement distribution by MNCs was forced to go through five Nairobi firms one owned by a powerful member of Parliament who not only was the Director of Lonrho (the largest MNC in Kenya) but is also a brother to the Chairman of Kenya National Transport Corporation (the largest transportation company in Kenya) and a son-in-law to the nation's president (Swainson, 1980:187). These bourgeoisie class also has been found to have a strong alliance with MNCs as it surfaced in 1973 boardroom crisis. During a struggle for leadership within the parent Lonrho Company at its headquarters in London, Mr. Rowland who had been accused of poor investments was saved by the Kenyan branch director from the threat of dropping him. Rowland's survival angered the British Prime Minister, Mr. Heath who called for the break up of the company (Swainson 1980:280). 
This disproportional distribution is further evidenced by the relationship between the Kenyan directors of MNCs and their shares of investments. In one study, two of the top ten directors (the fifth and ninth) owned the largest shares of the firms in which they were directors $(33$ and 20 respectively). On a profile of directors (the fourth and fifth), it has been found, for example, that the fourth director directed 36 firms holding a direct interest in 33 firms. His ties included the East African Breweries, saw mills, tea processing, a shoe factory, drugs and bricks manufacturing, a transport company, a line of Agip hotels, agriculture, etc. He is also a member of parliament and an Assistant Minister for Energy and Regional Development (Swainson and Weekly Review). The fifth director sits on 36 boards of foreign firms and 33 of which he owned partially or wholly including the biggest tourist hotel - New Stanley Hotel, Lyons Ice Cream, managing all the investments of 20 th century Fox, etc. According to the latest government reports into investigations of a former attorney-general, his influence includes kenya airways, port authorities, newspapers, and nearly all foreign firms with undetermined number of directorships.

Indeed, the gap is so wide that new MNCs still find it to their advantage to associate themselves with such personalities as well as having commercial links with establishments they control. An estimation using the Lorenz curve 
in 1962 shows that the top 18 of Kenyan population accounts for $18.5 \%$ share of the total income, the top $5 \%$ earn $44.3 \%$ while the bottom $5 \%$ earn a mere $12 \%$. The calculated Gini Coefficient was found to be 0.60 (Killick, E. African Econonic Review, Vol. 8, \#2:8). 


\section{MNCS POSITIVE CONTRIBUTIONS}

Very few studies have been done in kenya to show the positive contributions of MNCs compared to the negative impact. Indeed, those studies that show the positive effects are based on the same facts flipped on the other side. Thus, starting with the general effects analyzed above, these studies show that conspicuous consumption is a sign of progress. In Gunner Myrdal's growth model, the highest stage of the development path is the high mass consumption. Hence, imports are said to indicate availability of variety.

On the demographic distribution, it could be argued that population concentration in urban areas is only a natural process of demand and supply forces to reallocate factors of production. Given that there is higher demand for wage labor in cities than in the rural areas, it's natural that labor will move into cities. According to oucho and Makras (1984), their study reverses the negative connotation of rural urban migration. Through case studies, they conclude that both the urban and rural sectors have been in supportive of each other and that this migration especially into Nairobi has been of economic significance in the transfers or distribution of wealth to the rural areas. 
Other effects such as education have been said to promote not only managerial and administrative skills but also promoted the ability to detect and control MNC's unfair practices. The dualistic problem of the elite against the common people could also be analyzed on the basis of rural urban migration studies by indicating that the elite have something to offer to society too. And finally, with the exception of the few problems discovered in planning, the Kenyan plans have in most cases met their targets. 
THE ROLE OF MNCS IN ECONOMIC DEVELOPMENT

It is with this background that one can appropriately analyze the role of MNCs in Third World countries. Todaro has made some general observations about their contributions both negative and positive that fit the pattern we have just learned. One of the arguments he poses is that these foreign investments contribute by "filling in gaps between domestically available supplies of savings, foreign exchange, government revenue and skills, and the planned level of these resources necessary to achieve development targets."

The counter arguments challenge the above notion of gap filling in that foreign investors stifle competition, repatriate profits, charge high interest rates, diminish government revenue through liberal tax concessions, allowances and protection given to them. Todaro's study also found the problem of dualistic economic structures of inequality, introduction of inappropriate commodities, consumption patterns, technologies and monopolistic power, extraction of economic and political concession with reduced social returns.

Given such a situation where MNC's contributions to the economy have been impressive but with a big question mark on development, it is necessary that developing 
countries examine the nature of their economies, the structures of foreign investments and the needs of their welfare before assessing and validating their strategic development approaches. Here, I will observe some of the variables significant to the analysis and formation of coherent national economic policies. 


\section{POLICY REMARKS}

Policies aimed at correcting LDC's economic imbalances and problems will need to emphasis the role of government and the MNCs in the economy. It is hoped here that the direction of these two major variables are very significant with the observation that a symbiotic relationship need to be established between these two variables. In any case, however, the government should take the leading role and its objectives should prevail if there is conflict of interest.

Among the important variables to be considered are those based on the economic viewpoint. According to Pearson (1969:169) the good industrial policy in East Africa should be where the government control extends widely and more deeply than would be acceptable in a capitalist system, yet, less direct government involvement in productive activities than would be appropriate in a socialist society. Thus, this mixture of state intervention alongside private enterprise is what he calls "African Socialism": or "emergent capitalism". Pearson's three test criteria is to accept a project if it satisfies these questions:

"i) Will in increase national income?

ii) Will it earn or save foreign exchange?

. iii) Will it contribute to government revenue?" 
In sum, a government's policy should therefore focus on its responsibility of optimizing the available means to improve the welfare of its people. A social cost benefit analysis has to be evaluated before any policy is made and the longer the time period it can be forecast, the more reliable it can be.

To do this, the government should recognize that MNCs are very sophisticated enterprises especially those that are offshore. Other unique features to be carefully considered should include the proportion of intangible assets, the size of the corporation in terms of volume as well as geographical operation, its market of operation, i.e., whether more oligopolistic or more competitive by using the concentration ratio formula where if the four largest firms have equal or more than $50 \%$ of the market they are oligopolies.

on the other hand, the government should recognize that some firms will have positive effects on the economy in the long run and should therefore be encouraged through various means as will be pointed out later.

\section{The Role of Government}

The major significant factor is an effective and comprehensive plan. Thus the plan should be feasible, integrative and acceptable to the people of kenya and in the interest of kenyans. The main emphasis however should be 
to focus the participants towards the direction of the economy through inducements rather than dictating to them what to do, i.e., decentralized free market decision making. Among the inducements to be provided are low interest loans to acceptable sectors. This kind of inducement has been successful in Japan where the ruling party, which practically controls the major banks has been promoting industrialization. The same has been the case with the French Planning system which involves penalties and inducements. Given the fact that agricultural products fetch low income on world markets and yet modern industrialization has encouraged sophisticated labor saving technologies (as we have seen before) as well as income disparities, the plan should emphasis moderate intermediate technologies, such as product recycling, food processing, saw milling and other import substituting production. The advantage here is that some balance of payments problems will be avoided, agricultural surpluses will be reduced and because of their moderate capital and high labor intakes, the economy will avoid being locked into simple agricultural tools yet still offering employment to the majority. The fundamental issue, here, as Pearson has suggested, is that any project to be implemented should be based on whether it will (1) increase national income; (2) earn or save foreign exchange; and (3) contribute to government revenue (Pearson, 1969: $170)$. 
Along with this should be an education system that emphasizes technical training such as building and construction, improved agricultural techniques, carpentry, goldsmithing, business and other activities that train students for self employment rather than depending on MNC job openings. To encourage these young technocrats into the economy, the government should encourage co-operatives through inducements such as cheaper licensing, loans, extension services and major infrastructures. Co-operatives can be on an industry basis such as the dairy industry in Holland or on community basis such as the Chinese commune system. However, the government's decentralized planning system to the district level should be responsible for coordinating community co-operatives towards national planning goals. These co-operatives should be subject to anti-trust laws so that local competition is very much encouraged. This can follow the American model of breaking up big monopolistic companies. And at the same time, the Japanese policy of protecting large industries from outside competition but allowing fierce internal competition would be healthy. This can be done by subsidizing local research, awarding and protecting patent owners as well as encouraging local purchases of government and other organizations' supplies (i.e., the famous 'Buy Kenya to Own Kenya' slogan). 
Similarly important is to have experts make important decisions rather than politicians to avoid the "bits and pieces" type of projects and corruption.

Another area of focus should be resource distributions. A progressive tax on income and property (with Reaganomic type tax breaks where property is developmental) should be preferred against sales tax (except on imported luxury goods). The government subsidized loans should be selective to benefit the vast majority of potential producers especially in the rural areas which is better done on district than national level. Trade and agricultural shows should be emphasized to help educate prospective producers as well as making consumers aware of the products available. This will enable city dwellers to travel around their country and get to know their responsibilities as well as diverting their expenditures into the economy. More important is the imposition of high penalties for misuse of resources through tax refunds based on the income received from the property, e.g., a 10 s tax on land but with a percentage refund on income earned from the use of land and where chronic, a fine should be imposed when property is left unproductive.

Internationally, the government should have an open trade in the sense that there is no discrimination to particular partners in a given category such as within MDCs. The cheapest bidders and the highest offers should be 
considered. However this policy should consider the standardization of products to avoid being tied to one partner for spare parts.

secondly, the government policy should be pro the formation of custom unions, trade areas, common markets, and geared toward international and multilateral corporations, as well joining the commodity and cartel agreements than tying itself on individual partners. The exports sector should emphasize its focus on LDC consumers whose demand does not require sophisticated modes of production.

The Role of MNCS

The MNCs should be encouraged to make their investments especially in areas where local nationals are unable to invest and probably on turnkey type agreements such that after a given period of time, the operation should transfer to the local nationals.

The MNCs should observe the laws as well as ethical conducts such as avoiding political scandals and illegal repatriation of currency in excess of that established in their contract. The MNCs should also encourage fair competition in promotion of local efficiency without resort to predatory dumping and should use local resources as much as possible.

Both the foreign and local companies should develop a symbiotic relation in league with the government. The 
government should provide MNCs with available relevant information especially as regards the direction of the plan, and possibly be worked on the district level with the idea of product and geographical diversification. The MNC technologies should be compatible with the plan's requirements and provide the necessary link to the MDC sources and markets.

\section{Rejoinder}

In summary, the national policies should be comprehensive, decentralized, diversified and feasible. They should be for the good of the nation but with an acceptable international image. 
CHAPTER CONCLUSION

Given the current status of the MNC in the world economy and more specifically to the kenyan economy, we would conclude that a national policy to deal with MNCs should focus on the variables such as the theoretical and empirical evidences of why MNCs exist in the first place. This should be done with reference to the historical and current economic trends within the country with the aim of deducing the possible impact of the MNCs on national policy making. In this chapter, we observed that Kenya's vital economic decisions have almost all been made by non-nationals. First were the British colonists and then the multinational firms. In both the cases, we found out that the rationales for most of the decisions were either based on the notion of comparative advantage or profit maximization. The effects caused by these decisions were examined, with the use of data and general observations. From these studies, suggestive policies were made with specific emphasis on the role of the government in directing economic decisions and the MNC's symbiotic relationship. Gathering from these, we can conclude that Third World countries' economic development and policies should not emanate from without but indeed, the fuel, the engine and the steering wheel should 
come from within, focused on the interest of the majority from within and shouldered by all from within. 


\section{FOOTNOTES}

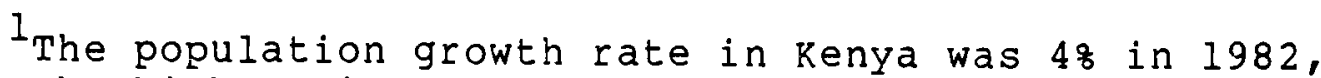
i.e., the highest in the world.

2 Economic survey, 1973 , pp. $38,66-7$. Brooke Bond Liebig, Kenya Ltd., Annual Report 1972, pp. 3, 6. Langdon, p. 32 .

${ }^{3}$ s. Langdon, The Political Economy of Foreign Investment, Mimeo, 1976. Swainson, p. 215.

${ }^{4}$ see the British Information Service, Kenya: Progress and Problems, 1960, p. 5 .

${ }^{5}$ Annual Returns of the Registrar General, summary of Yearly Statistics, Swainson, p. 195. 
SECTION TWO

SPECIFIC ISSUES

In section one, the general economy was examined. Chapter I dealt with theoretical issues that map Kenya in the world economy. Chapter II bisected out the industrial economy that is related to the MNCs. In this section, we deal with specific issues that concern MNCs' effects on Kenyan economic development and policy making. These are our leading issues as the title of this section suggests. Initially, a variety of issues will be tabled in general terms with LDCs' complaints about MNCs stipulated first and then followed by interview responses from MNC executives in LDCS. In order to examine these issues from all angles, each particular issue will be first applied on the general economy. Then next particular economic variables such as labor in Chapter III, rural areas in chapter IV and ideological issues in chapter $V$ will be examined in terms of all these issues in general.

We have briefly noted some positive contributions of MNCs in kenya with a lot of negative effects. But as I have already noted earlier, this thesis is to explore some of the notable and acceptable activities of MNCs in LDCs and particularly in kenya. It is only from recognizing the MNC problems from both ends that policy making cannot only 
be more objective but also beneficial for the symbiotic relationship between LDCS and MNCs economies (putting the North/South politics aside).

In this section, a variety of specific issues will be set forth. This would be some of the significant issues that LDCs have felt the MNCs have failed to characterize in order to contribute to development. Each issue will be followed by a response from interviews that have been carried by Frank among the MNC executives from the North indicating the denials or justifications of the way MNCs behave in LDCs. These issues will set the theme of the rest of this section. Some of the problems and other related issues from these interviews will be discussed as they relate to Kenya. Then in Chapter III we shall discuss some of these issues as they relate to labor and resource employment in Kenya. In Chapter IV, these issues will be discussed in terms of the development of rural areas and in Chapter $V$ their relation on ideological issues will be analyzed.

All in all, these issues will help us in the search for policies and solutions less radical but equally or more appealing to the development of Third World economies.

One of the issues involves investments. Thus, first the complaint has been that existing firms may be forced out of business or may decide to sell out to the Multinationals. Moreover, barriers are created to the entry of 
new, indigenous entrepreneurs as a consequence of the advertising, promotion and product differentiation practices of MNCs. Secondly, this later practice stimulates demand for types of products too sophisticated or inappropriate to a poor country's stage of development. According to Frank's interview, most British and Japanese denied experiencing competition except from other MNCs due to their own corporate policies. The British firms invest in sizeable markets not being serviced efficiently and move out where locals have been effective competitors. The Japanese do not produce for local use but to sell in Japan and other markets and therefore are not competing with locals.

In general, MNC retailers claimed they tend to appeal to higher income consumers by expanding that market because of their quality standaris and therefore create their own markets than compete for existing markets. They claimed that it is their technology, know-how, and capital which are beyond capabilities of local entrepreneurs rather than promotional advertising and other marketing advantages that gives them an edge over locals.

Another issue has been that MNC firms have been in the best position to take advantage of LDC policies in conserving foreign exchange and encouraging industrialization through high degrees of protection. Hence, the stimulus to industrialization often fails to benefit the indigenous 
while it is the local economy that bears the cost in terms of higher prices which MNCs take as excessive profits.

In response, one U.S. Firm claimed that it only produces abroad in order to obtain foreign exchange with which to import its own products. Thus B's subsidiary might produce commodity $x$ in kenya for exports to obtain foreign exchange in order to import its commodity $Y$ for selling in kenya. In any case, the firm claimed that import restrictions are imposed for balance of payments reasons rather than protecting local industry. The electronics and food processing companies, on the other hand, indicated that they go abroad to take advantage of cheap labor and other factors of production, i.e., in spite of protection measures.

Foreign firms have also been accused of refusing to unbundle their investment packages which in some cases contain investments of strategic national importance and could be at lower costs if operated by government (e.g., utilities). Frank's findings indicate that extractive industries are more willing to unbundle than manufacturing industries because of national sensitivity to such operations and also due to lesser flexibility of extracting companies to chose countries in which to invest. Another reason leveled by MNCS is that LDCs consider $R$ and $D$ costs as sunk costs and are unwilling to offer reasonable fees. Hence, MNCs are unwilling to sell off such operations. 
'One Shot deals' were seen as unattractive financially to firms and they are not interested in helping to establish competitors either.

critics have pointed out that foreign operations are not foreign "investments" in the real sense because they commit a small amount of their own capital preferring instead to borrow locally as studies show that only about a quarter of foreign investments in manufacturing are directly financed by parent companies. This is seen as detrimental to local enterprise. MNC's main reason for borrowing were said to be minimization of risks such as currency depreciation, inconvertibility and exposure to nationalization. A British and a German firm claimed that actually MNC investments have increased the supply of funds to local firms by bolstering the confidence and willingness of financial institutions to lend to domestic ventures. And because of restrictions to repatriate profits, most firms have also reinvested or lent the funds to financial institutions for investment borrowings locally.

on the issue of takeovers, it has been found that almost a third of all MNC subsidiaries in LDCs have been through acquisition which is regarded as an alienation of domestic economy as well as reduction of competition and increase of affiliate's dominant position. However, the MNCs have claimed that take-overs benefit host countries from the infusion of capital, technology, and managerial, 
marketing, and technical skills. For unsound firms, acquisition prevents certain dislocations associated with business failures and their parasitic effects on the economy. Further, acquisition may be more efficient and benefit LDCs through employment opportunities, upgraded skills and potentially low prices for locally produced goods than if they were to import.

A more controversial issue has been the transfer of technology. These have been too sophisticated, highly designed and elaborately packaged to meet the needs of poor masses. Also the technology is inappropriate since they are capital intensive in relation to LDC's excess cheap labor thereby intensifying unemployment problems, aggravating inequalities in income, worsening balance of payments by capital imports and even inputs.

The MNC interviewed responded that local raw materials lessen quality given that their appeal is for the high income market. The British and French MNCs emphasized standardization and reputation of uniform quality and companies in pharmaceuticals insisted on their image of not cutting corners to adapt to local needs because it would give a bad publicity. And in machinery circles, interchangeability of parts makes standardization necessary and therefore an MNC would rather train the local personnel (as we shall see in the General Motors case) than try to adapt. 
Other arguments were that automated process may even be preferred because they often require less skill than labor intensive processes, that LDC policies especially on restricting employee dismissals encourage use of capital and even over-valued exchange rates and tariff concessions. On licensing and patenting, LDCs have complained about the prices charged, conditions attached such as purchasing materials, components or equipment from the licensor, limitations in the scope of market and grantback provisions. MNCS' response has been in defense for their competition with other foreign subsidiaries, the restrictions protect their quality and image internationally, high prices are due to high research costs, etc.

Related to the issue of patents is the issue of $R \& D$. Not only have MNCs been accused of failing to establish $R$ \& $D$ in LDCs but they have also caused brain drain through emigration of scientists and engineers in search for higher salaries and research facilities at MNC's home countries. In response, the MNCs have claimed each situation of locating $R \& D$ is unique, e.g., a mining company will establish its $R \& D$ at source unlike a pharmaceutical company. Other firms argued that shortage of skilled personnel locally, inadequate market size, etc., makes it uneconomical to establish $R \& D$ in most LDCs. Hence as an alternative, most MNCs contribute financially and/or technologically to local facilities, universities and established research 
institutions. This was particularly noted among the U.S. firms but other European firms would do so only when the research is "highly relevant".

In terms of employment issues, most LDCs were found to have legislation on training, upgrading, limitations on the number and type of foreign representatives, job protection and other labor practices. The MNCs claimed to have observed those rules and in fact their employment practice standards exceed requirements of most host governments. The only problem has been seen when those rules discriminate foreign firms and therefore resorted to capital intensive technologies. Most firms reported to other training domestically, abroad both on job and/or training institutions. The Japanese firms prefer on-the-job training.

The issue of economic linkages (both backward and forward) has mainly been in the form of trying to integrate foreign and local firms by requiring increased content of local value added, prohibition of inputs in their raw state and encouragement of further local processing, increased use of local engineers and consultants. Few companies have had a problem in backward linkages. However, most, especially extractive firms find it difficult to provide any forward linkages locally because of the required heavy capital. This is crucial in the Philippines where foreign equity ownership depends on the level of processing obtained locally. In our case, the kenyan requirement (mostly 
saving foreign exchange in terms of increased exports - and 1984 is the export year) is not very extreme. However, most firms (but least among Japanese firms) satisfy this condition through subcontracting.

The last issue we shall consider in our findings is that of transfer pricing. Critics allege that prices often diverge from arm's length prices that would prevail under market conditions thereby benefiting MNCs to the detriment of host countries. The MNCs however argue that there is no basis to value these transactions due to their specificity to particular situations of research and this is mostly within companies with a high degree of centralization. other firms claimed the extra costs to be due to host governments' restrictions on royalty payments, $R$ \& E fees, limits on dividend and other price controls. Moreover, the British, American and German firms face some regulations from home that limit this practice as well as the bilateral and multilateral agreements between countries.

These and many more issues are only some of the problems mushrooming between the MNCs and LDCs relationships. As I have mentioned, these issues will be recycled in this section under various particular topics as they relate to MNC effects on Kenyan economy. But first, we dwell on some that are general to all topics that we shall and shall not deal with. This will be in the form of some empirical findings so far. 
One such issue that has been of particular interest in Kenya is that of transfer pricing. The ILO in Kenya found evidence of overpricing of imported intermediate goods from the parent company to the extent of 20 or 30 percent more than these goods would fetch on the open market (swainson 1980:221). ILO's estimate in 1971 in Kenya was said to have more than doubled the real outflow of surplus from the manufacturing sector as compared with declared profits and dividends. This sparked the kenya government to hire a Swiss firm to check on over-invoicing (Swainson 1980:222). According to Collin Leys' (1974: 126) writings,

Another practice which effectively circumvented exchange control was the payment of management fees, consultancy fees, and royalties for patents, brand names.... The ILO mission studied a sample of ten foreign manufacturing firms and found that in 1971 such payments constituted $40 \%$ of total remittances, and were equal to $67 \%$ of dividends ... The 1971 budget had imposed a special $20 \%$ tax on such payments and ... Many companies which had been making all the three payments preferred to go on making them and pay the tax, rather than scale them down ... even in the face of tax ... expanded exchange-control ... to probe such practices... "but" ... Kenya's position as a periphery center offering an attractive location for the regional operations of international companies meant that the government could not easily afford to become too strict about such matters even if it could muster the technical expertise to police them.

And according to Leys, as can be seen on the table below, net private transfer pricing between 1964 and 1970 was K.E4.7 millions. 
The other issue is related to competition; whereas it is an established fact that foreign firms have tended to monopolize Kenyan markets and therefore lessened competition, it is also true that some have fostered competition. For example, in a special bulletin as "Focus on Computer", the weekly review of Kenya made an analysis on the effect of ATT's entry into the market will provide a solid alternative to IBM and is likely to price at 10 to 15 percent below IBM thereby affecting Apple as well. One financial analyst, Douglas Cayne, has even suggested that IBM's recent announcement that it would cut prices by between 18 and $23 \%$ is related to ATT's entry (Weekly Review June 22, 1984: 43).

Several other firms have too been found to compete each other effectively that their monopolistic practices are limited to few situations. However, foreign firms' domination of the market in kenya can not be wholly dismissed. According to Pearson (1969:133), the Bata shoe Company dominates the Kenyan economy with a growth rate averaging over $10 \%$ per annum. This kind of domination often ends up to be exploitative as exemplified by the Brooke Bond Tea Company in Swainson's (1980:26) study. Through its small holder scheme, the firm has been paying very low prices for collecting the leaves for processing that one farmer was outraged to write a letter threatening to . "follow the good example set by the Meru farmers ... and 


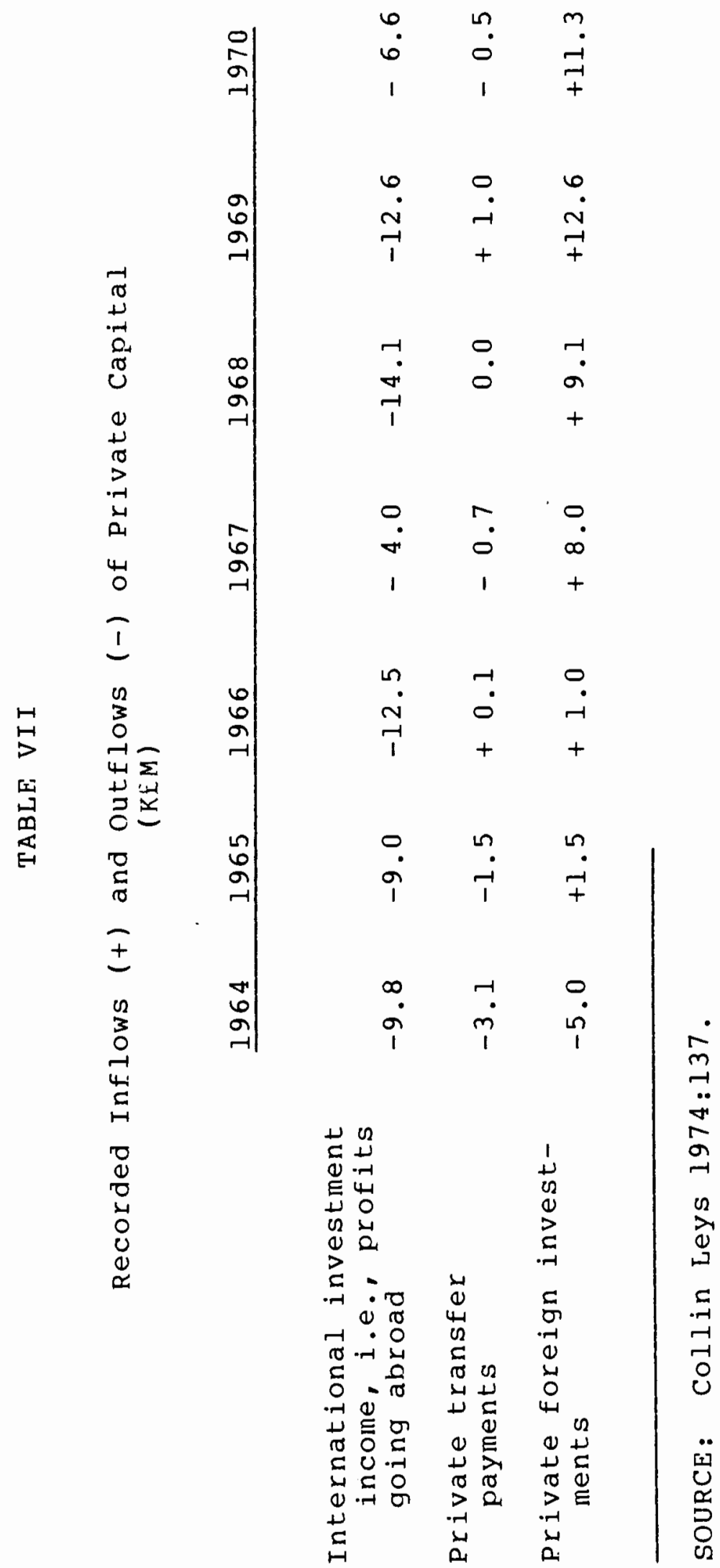


I will go in for potatoes, vegetables and cattle which pay more in comparison" (Daily Nation, september 20, 1977). Brooke Bond's policy of controlling plucking standards has also meant that it will be able to purchase the higher quality smallholder tea and blend it with its own lower quality tea (Swainson 1980:258).

The benefits however have equally been of significant weight. For example, the Kenya Breweries have had a selfsufficiency that has saved Kenya millions of shillings in foreign exchange. According to the special Bulletin on "Focus on Kenya Breweries" (Weekly Review, March 2, 1984: 23) the brewery contributed KE78 million in 1983 (an amount sufficient to finance one of the larger government departments for an entire year). Others have provided an easy means for the government to take over as was the case in 1969 when the government took over Liebig's meat production firm at Athi River (now the large Kenya Meat Commission [KMC]) as well as Brooke Bond (third largest foreign firm by asset value, 1972) which was forced to sell its shares on Nairobi's Stock Exchange (Swainson, 1980:255257).

other benefits include general increase in manufacturing investments. According to the speech delivered by the Chairman of Kenya Association of Manufacturers (Weekly Review, December 16, 1983:20), the manufacturing sector has been growing at an average rate of $9.8 \%$ per annum. Hence 
only 148 of imports constitute consumer goods compared to over $80 \%$ at the time of independence (i.e., 20 years ago) which implies a developed industrial base to satisfy consumer needs locally.

All these generalities in one way or the other affect the national economy across all sectors of the economy. It's now time to relate some of these particular issues to particular topics I have chosen for the analysis due to their importance in the kenyan case. 
CHAPTER III

\section{LABOR RELATED ISSUES}

\section{Employment Problems}

Labor is one of the most critical inputs and plays a very significant role in development. Not only is it productive, but it is also the only factor input that can make decisions on its productivity and can force to alter the trend of operations. Hence the level of national employment, productivity per worker, etc., are among the important factors in the measurement of the economy. The MNC's effect therefore on such a factor is worth examining.

It has been known that most of the labor force is employed in the agriculture sector in kenya due to high subsistence that persists in the economy. For example, according to Kenya's official handbook, in 1980, agro-based industries accounted for $55 \%$ of employment and $65 \%$ of the manufacturing sectors share in gross domestic product with major contributors being sugar processing, confectionary textiles and garments, wood and wood products, pulp and paper, fruits, etc. ${ }^{1}$ The MNCs have had both the negative and positive effects in this sector. For example, because of their capital intensive techniques, the amount of labor used has been proportionately low. In a study done by Swainson on tea production in Kenya, it was found that the 
Brooke Bond Liebig Corporation has employed the CTC method of production which has become popular in the world tea industry and was introduced into Kenya in the early 1960s. This method chops up tea finely by tearing. The method was followed by the G.W.A. system of fermenting. Both methods were meant to save time and give careful control respectively. However, this technique has also called for improved plucking techniques in order to improve the labor productivity. As Swainson has indicated, cost of production has fallen since 1958, and 12,315 people have been employed, 121 in management, 189 in supervisory and 10,915 as staff (Swainson 1980:253). Thus, on one hand, the Brooke Bond Corporation's technology has been labor saving while creating employment in other sections. Being the largest tea corporation in the country (with more than 858 share) besides its employment of labor on its tea estates, other private large and small farms have been created due to its increased output. As we saw from the previous chapter, tea is the second largest export good of Kenya. Consequently, any effect in the production of tea would have an impact on the nation's economy.

The MNCs should therefore be sensitive on labor issues especially in sectors that affect the national economy. Their technologies should be able to make up for lost employment in some other way because labor is a very sensitive factor of production. The major problem however is 
that most MNCs don't go into agriculture which supports the highest level of employment and are therefore seen as promoting their own interests. For example, according to the ILO mission, foreign manufacturing firms in Kenya were more capital intensive than their local counterparts. Hence total employment in these firms rose by 28 per annum from 1964 to 1969 while output rose by 9.86 (Leys 1974:138). Implicit in this data is the fact that the capital used was labor saving. However, it also increased productivity per work. Consequently it is very hard to judge the kind of impact this has created without further investigations.

Another product that has interested MNCs from early days is the fruit industry. The first incidence started with three British firms in the processing of canned pineapples with Renyan canners employing 808 of the industry's labor force in 1957. By 1961 it employed 400 workers and by 1976 it had over 10,000 workers. However, unlike the tea industry which encouraged outgrower farmers, the pineapple firm destroyed the outgrower system. Thus, in the 1960s, the British companies sold to Calpak (now Del Monte) all their pineapple firms which were consolidated with the government's approval. Calpak embarked on a very intensive modern scientific technique on its enlarged estates and consequently refused to process the outgrower farmers' pineapples. In spite of the positive effect on increased quality and therefore high exports with saved foreign 
reserves, Del Monte's image was tarnished as a monopolist firm with the aim of making profits. First it had replaced the three competing firms. Then it replaced all pineapple farmers. Even with increases in firm employment and including all other merits that it created, the common person had a different perception of Del Monte. Implicit in this situation is the fact that MNCs should focus on all angles and especially the most sensitive areas or else all their merits won't count. Indeed, by employing few technocrats, Del Monte contributed to the situation of income concentration among the few elites as we shall observe in the income distribution section by having a few people employed in the place of many farmers.

The Bata shoe Company (B.S.C.), a British firm with more than $80 \%$ share of the shoe market, is another example of intensive technology that is labor saving. Unlike the Calpak (Del Monte) situation which exported most of its products and therefore saved foreign reserves, the Bata Company produced cheap, low quality products for local use. According to Swainson (1980:166-169) Bata produced eight million shoes of which only two million were made of leather and six million from textile, rubber or plastic. Consequently, instead of earning some foreign exchange, Bata was only making profits in Kenya. Langdon has noted that Bata's sales in Kenya expanded by $66 \%$ between 1967 and 
1972 while in 1974, the company made a profit of KE 1,042,961 (Swainson 1980:268).

To make the situation worse, B.S.C.'s intensive techniques were applied on those low quality shoes that were produced in large quantities and therefore foregoing more labor employment. For example, in 1955, 500 workers produced 1000 pairs of shoes per day made of leather while the low quality shoe section employed only 200 workers who produced 1500 pairs a day (i.e., the ratio of $2: 1$ and $7.5: 1$ shoes per person respectively). In 1970, B.S.C.'s 5.5 million shoes were from rubber and employed 650 workers while two million pairs were of synthetic and had 400 workers (i.e., a ratio of 5000:I and $8462: 1$, respectively). This does not only show how the latter is more labor saving than the former but also indicates how B.S.C. In fifteen years has drastically emphasized capital intensity, i.e., from $2: 1$ to $5000: 1$ and from 7.5 to 1 to $8462: 1$ in fifteen years, respectively.

In terms of making boots, the old method produced 500 pairs of boots using two workers, i.e., 250 each while the new method needed 35 workers to produce 800 pairs, i.e. 22 pairs each. Hence, when in 1974, B.S.C. had doubled its employees from the 1954 figure, the output was five times that of 1974. Hence not only were the low quality shoes neglecting contribution to foreign exchange but were also labor saving. Compounding this effect is the fact that 
this same low quality shoe used the imported inputs. Since B.S.C. is a globally integrated company, it imported inputs from its own subsidiaries. For example, in the $1950 \mathrm{~s}$ B.S.C. obtained its rubber from its own west African plantations. We can therefore safely say that the B.S.C. is an example of a corporation that will cause love/hate relations between MNCs and the nationals. Most often, the bad effects are echoed highly that they generally overshadow contributions of corporations such as of Brooke Bond that we saw earlier and many more others. Such contributions include saving foreign exchange, increasing output and generating high standards of living through employment and labor training.

One area that MNCs have positively contributed to Kenya's labor force is the training of their workers. In 1970, the Kenyanization Bureau was strict on the schedules of replacing foreign expatriates through the provision of training (Swainson 1980:233). Based on this program, the Kenya National Trading Corporation was set up with the first goal of assisting Kenyanization of commerce (Government of Kenya, official Handbook 1983:101). As a result, most corporations are engaged in labor training. Indeed, the effect has been increased employment levels and greater worker participation as evidenced in the kenya Breweries Company (KBC, the largest brewing company). The company employs 4,000 people and almost all of them have shares in 
the company. As KBC can now claim "No other company in Kenya can match this record of worker participation in the equity of the employer's company" (Weekly Review, March 2, 1984:19). KBC also obtains all its raw materials, goods and services within kenya. The industry has backward links to agriculture in that about 1,500 Kenyan farmers supply it with barley and have greatly promoted the glass industry too. The company has an intensive training program for all parts of its operations including engineering, chemists, truck drivers and even farm workers. In 1983 alone, KBC spent 1.64 million shillings to keep its training facilities at the highest level, its workers are among the well paid with better benefits including housing, interest free loans, clinics, medical care with their own village in Nairobi consisting of schools, shops, a cinema hall, sporting facilities, etc.

Other corporations with similar attitudes include the sugar industry which employs over 500,000 people with about 50,000 others as outgrower farmers (Weekly Review, sept. 23, 1983:26). The General Motors Corporation which now employs in excess of 16,000 people, passing technology and management skills to kenyans through training and actually providing some exports to neighboring countries (Weekly Review, Nov., 18, 1983:24). Indeed, Kenya has benefited from foreign firms mostly through their exports to the neighbors or through its centinpatal effect in the region 
such as the establishment of regional offices in Nairobi. The Shell Company was the first followed by British and American Tobacco (B.A.T.) and now most corporations in the region have their offices in Nairobi thereby creating employment at home and those sent abroad.

As a result, the employment statistics in kenya are impressive. Thus wage employment rose from 49,500 in 1964 to 62,594 in 1977 and to 70,504 in 1980 in commerce and industry (Government of kenya 1983:97). And in 1983, the recorded number of wage employees in the northern sector went up by 47,300 , i.e., 4.5\%. Wage payments rose by $11.4 \%$ with an average wage earnings rise of $6.6 \%$ (Economic survey Report, Ministry of Finance, Weekly Review, June 15, 1984:21 and Appendices 8 and 9).

In an overall assessment of the MNC's impact on labor related issues, we can assert that there has been a.positive and negative impact. The negative impact as that portrayed by the Bata Shoe Company which used sophisticated technology, few workers, imported raw materials and yet sold most of the goods in the country is very discouraging. In spite of other developmental effects it might have added into the economy, the overall picture is that of quick profit making that can easily call for an outrageous perception of all foreign firms. On the other hand, the records of firms such as kenya Breweries are very impressive and encouraging. The impact is developmental, domestical and 
patternal to the indigenous. Consequently, in terms of policy making, evaluations would better be carried on individual firms basis in order to promote kenya's economic development.

\section{Employment Determined Income Distribution}

Probably the significant effect that the MNCs have had on the Kenyan economy is industrialization. We have already observed the growth of industries in general, how their location has been used to earn foreign exchange through exports to neighboring countries and how it has affected the national policies of development. In the case of income distribution, as a labor related issue we have observed that the hiring policies have helped the rich more. Thus, firms have often hired people based on their political status in spite of the highly qualified personnel there are on the streets.

on the other hand, the more popular someone is in the political arena, the more job offers $s /$ he will get as well as the higher are the salaries. The consequence has therefore been a very unequal distribution of wealth in favor of very few individuals as we noted in the previous chapter. Another touchy area is the kind of technology used. The MNC firms are usually from technologically advanced countries which has been improvised to save costs such as labor costs. Hence the introduction of such technologies 
has a great impact on labor in general as well as income distribution. Thus only the lucky few will get employment. And in view of what we have learned from the previous findings, it's again those with political ties; the elites and those who already have large enterprises to be taken over by MNCs. Here again, the scale is tipped toward the few and therefore poor resource distribution.

However, it is not all gloomy. Some MNCs technologies have been very contributive to economic development. For example, whereas some companies introduce their own technologies, some like Brooke Bond do their own research local1y. Brooke Bond sponsors the Tea Research Institute at Kericho. Thus, local personnel would have an opportunity to advance their careers and some of them could start their own businesses (Swainson 1980:253). The sugar industry is another example that is involved in local research especially through the kenya sugar Authority that undertakes research on soils through the country. This technological boost has mainly come from Five-Cail Babcock, a French firm at Nzoia (Weekly Review, sept. 23, 1983:26). Not only does this research provide job opportunities but their local flavor also blends in the consideration of labor generating than saving techniques. Hence, even if the technologies that have been imported have caused poor income distribution, some companies have come out with impressive performances that are worth encouraging in the sphere of 
technological advancement. We will note ahead under the impact on agriculture how some of these corporations' technologies have indeed increased productivity per worker and per acre. We will also note the high quality that effectively competes on world markets thereby importing or saving some foreign reserves. 


\section{SUMMARY}

Thus in this chapter we discovered some positive characteristics of MNCs in their effect on employment. This has been through improved technology, increased training and many more social activities. The issue of income distribution was also observed with mixed characteristics. However, the stereotype negative effects leveled against MNCs were counterbalanced by the research activities that MNCs have helped to promote and thereby increasing technological advancement - What schumpeter would consider as the major force behind growth and development. 


\section{FOOTNOTES}

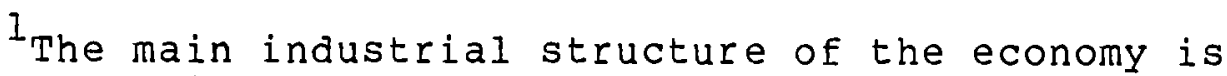
based on agricultural production. Kenya - Official Handbook 1963-1983, Government of the Republic of Kenya (1983). 
ISSUES AFFECTING RURAL DEVELOPMENT

\section{Agricultural Transformation}

As we saw earlier, Kenya is mainly an agricultural country and therefore agriculture touches every sphere of the nation's economy. So too are the MNCs. Indeed, the MNCs have not been very active in this sector in relative terms to the size of the sector compared to other sectors. However, the few that have participated have had very effective impacts especially in terms of forward and backward linkages. But before we examine these effects, we shall peg out points of view on particular empirical and theoretical studies that relate to the economies of agriculture. According to Colman and Nixon Simon Kuznets (1961) summarized the benefits of agriculture to development in three ways. First was product contributions in which food for the population and industrial crops for non-food uses are provided directly from agriculture. secondly, agriculture provides surplus labor for industrial use and net capital outflow for the industrial investments, i.e., factor contribution. Thirdy, is the market contribution whereby agriculture provides revenue to farmers for industrial expenditures. Within all these three categories we find that there are backward and forward linkages to be 
generated from the agricultural sector. It is therefore upon the MNC to choose which linkage it can provide as well as it is to the policy makers to decide which MNC is development oriented in terms of agriculture (Colman \& Nixon $1978: 132$ ).

Theoretically it has been accepted that the higher the income, the higher is not only the quantity demanded but also the higher the quality of products demanded. Hence,it is fitting to use kuznet's summary in this perspective in that as farmers' income increases, more goods in the economy will be purchased as well as more increased demand for industrial products thereby promoting industry. Consequently, if the MNCs have to grow in themselves, they would better encourage new ventures into agriculture as well in order to fetch for their own industrial markets (Colman \& Nixson 1978:132).

one of the factors disturbing LDCs' relation with MNCs has been technological importation. Unlike manufacturing however, agriculture is less mechanized and more labor intensive. But within the agricultural sector itself, the capital intensity varies. Hence the choice of agricultural development strategy has to be made. Thus should farming, for example, be large scale or small small scale. Before coming to LDC conclusion of relating the size of farming scale to the technology as in the case of Argentina and other Latin American countries whose lalifundio farms are 
large and heavily mechanized compared to minifondios and microfundios which are small plots of land cultivated with simple tools (Todaro 1977:260). In this case therefore, an MNC or LDC decision maker looking for capital intensive strategy might choose the large scale farming. However, Erom Colman \& Nixon's observation, Johnston and killby (1975: Ch. 4) have classified the agricultural development strategies into two, i.e., unimodal and bimodal. The unimodal strategy is small scale but it is biologically technologized as is in the case of the Japanese and Taiwanese development pattern, i.e., high yielding hybrids, multiple cropping, intensive irrigation and fertilizer application, etc. The bimodal strategy, on the other hand, is large scale along side small scale as is the case of Colombia and Mexico where large farms are more mechanized (Colman and Nixon 1978:148). Based on these strategies, a decision has to be made that will not only have a positive impact on agriculture development but also as we have suggested, it should have some backward and forward linkages such as on labor, industrialization, income distribution and the general economy at large.

Another developmental strategy that has been widely recognized is that of land reform. This may involve more redistribution of property rights such as having title deeds, land consolidation or even in cases of Mexico where large chunks of lalifundia were purchased to relocate the 
landless and the case of Kenya where large farms were subdivided to medium sizes to fit Africans' scale of production.

In all these cases, the primary aim has been to foster development. Based on these findings, we can therefore determine the impact of MNCs on Kenya's agricultural sector. We have seen effects of some of the major corporations such as Brooke Bond Liebig, Bata Shoe Company, Calpak (Del Monte) in terms of labor saving levels. Now we shall examine more in terms of technological imports and the linkages that have been hindered or created.

In the case of tea production, Brooke Bond planted its own tea on large estates. It also encouraged large scale and small scale farmers to sell picked up tea leaves to it for processing. Hence, in order to increase the quality of tea, Brooke Bond introduced a technology in which only the top two leaves were to be plucked for processing. The impact was that the technology was scale neutral in that it was applicable to both large and small scales. Indeed, it didn't need any mechanization nor labor layoffs. But the quality standards were so attractive on international markets that further land was induced into tea production as a form of backward linkage. On the other hand, a packaging and distribution network was set up at Kericho (a small town where Brooke Bond's factory is located) to cater to the firm's needs to commercialize their product both 
domestically and abroad. Implicit is the forward linkage which Brooke Bond can now bargain on for various concessions from the government. In short, we can suggest that an MNC that introduces a technology that is counter-reactive both backward and forward as did Brooke Bond not only stands a better chance of surviving and benefiting but also positively contributes to development.

Another significant case involved the Pan Paper Mills at another small town (Webuye). Being the largest paper mill on the continent, the Pan Paper has transformed this small town into a business enclave of printing presses, box manufacturing, packaging and wrapping operations and other indirect linkages such as residential buildings, shopping malls, health, educational and social facilities including agriculture, etc. The sugar factory complex at Nzoia is yet another related example. So are enclaves such as the Yuken (Yugoslavia/Kenya) textiles at Thika, the uplands Pork and Bacon Company at Uplands (named after the company) and the Limuru town which has come up through tanning related products. All these examples represent major impacts on Kenya in that they were started by MNCs in remote areas and turned these areas into large urban centers with many functions but all resulting from the agricultural operation that was started by an MNC. All have had forward and backward linkages. Indeed, some have been of such a landmark such as Uplands Company that people can't tell whether 
Uplands is the name of the major company or the name of the township. These examples also explain how MNCs and LDCs can benefit from the promotion of agricultural related operations. Not only do the MNC develop a long lasting opportunity but the LDC also learns to trust the corporation as a development strategy rather than a profit making alien entity.

It is with such contributions that Kenya's agriculture has sustained its development pattern. Indeed there have been a lot of setback corporations as we saw in the case of Calpak.

\section{Urbanization}

We have already noted that urbanization has caused some harm to the rural areas. However, this was in the sense that only a few urban areas are absorbing all the development opportunities. The question here is whether this has been a threatening case in Kenya. Whereas this is true to an extent, our study on agriculture in this chapter indicated that some MNCs have started in remote areas and grown up by creating new urban centers as is the case of Nzoia, Thika, Webuye, Limuru, Uplands, etc. All these are agricultural related centers that now rank among the top cities. It is also worth noting that some many more as we saw in Chapter II under Industrial Development have mushroomed due to other related operations. Hence, even if the 
MNCs can be blamed for concentrating in urban areas, some many more have interested themselves in rural development. This situation has had an impact on both demographic and economic gains redistribution. The population migration has been helped to diversity and therefore the economic benefits too. This can be cited in the current development plan (1984-88 Plan) whose theme is development on district levels. Thus, the District officer is in charge of development projects in the district and not on a national basis. This way, the political forces will help distribute industrial operations away from magnetic enclaves of Nairobi and Mombasa. On the other hand, those MNCs that have always operated in rural areas with poor communication links, complicated administrative bureaucracies and other infrastructures can now be paid attention to, to help them contribute effectively to national development. They can also be conveniently checked when they are not conducive to progress.

\section{Rural/Urban Migration}

It is a well known fact that the rural sectors are usually agricultural while the urban sectors are industrialized. In chapter I we saw how the rural sector has been squeezed out off its labor force because of the education system and employment expectations. In this chapter 
earlier on, we found out that agriculture has supplied its labor force to the industrial sector which in this sense means rural/urban migration. As Todaro has pointed out, most of the migrants are of the working age, the educated and mostly from the rural areas than from other urban centers. Our interest here is to find out how the MNCs impact has influenced this trend.

Whereas it is baseless to argue that the MNCs have been responsible for this disproportionate distribution of the Kenyan population relative to work opportunities, there is some evidence as we saw in the section dealing with industrial development that supports this view. Thus, most of the MNCs have preferred to locate their operations in urban areas than in rural areas. For example, Nairobi, Mombasa, Nakuru and Kisumu are the industrial magnets in the country with many MNC administrative offices and industries. A corroborating factor as we have already indicated is the fact that most MNCs are not involved in agriculture and logically therefore cannot be found in the rural areas where agriculture is dominant.

The ultimate fear of the rural/urban migration is the stagnation of the rural sector due to loss of manpower, on one hand and the urban unemployment and crime that increases with the level of immigration on the other. It has however not quite been established that the rural sector in Kenya has lost that alarming number of workers. Some 
studies have actually shown that a principle of economics is involved. Not only have the benefit/costs analysis been calculated by the rural emigrants but Oucho and Makras have found out that kenyan new migrants into urban centers have been a major link between the rural and urban areas. They frequently communicate back and forth and since they are not secure in their new environment, they keep holding the strings back in the rural areas in the form of investments, gifts and even politically carrying transformation messages to the urban administrative centers. However, on average, the MNCs location in urban centers and their disinterest in agriculture has a lot to say about the unequal distribution of income, social amenities, development opportunities, etc., between the rural and urban areas. They have a lot to say about the false expectations of the young generation in terms of education, job opportunities and life in general. So, too, are the urban crimes due to frustrations, health hazards due to increased slums, poor sanitation, industrial fumes and other related social activities. It is upon the MNC and the government therefore, that coordination of operations is balanced in a way that rural/urban migration is not a development hazard.

One thesis on rural underdevelopment has been that of labor loss to the urban centers. According to the dependency school of thought we saw earlier, the urban centers act as magnets attracting all the economic resources from 
the rural periphery. On the other hand, they also absorb all the external economic resources thereby denying the rural areas any access to such amenities.

Since labor is more mobile, it has been at the center of these discussions even more than other factors. The main causes have been attributed to the MNC locational policies as well as the education system which indirectly is also linked to the MNC operations. It has been argued that because of the possible job opportunities, luxurious living standards created and the non-laborious technical kind of jobs provided have inappropriately influenced a stream of labor immigrants floating in urban areas unproductively. Therefore, it is further argued, the rural areas have lost their previous trades and are further to lose future opportunities.

It is debatable as to whether the MNC holds all the responsibility of rural underdevelopment. Whereas studies like those of Oucho and Makais are in favor of this labor migration based on their findings it is equally true that the MNCs have also helped to diversity labors points of immigration as well as broadening their sphere of experiences. Given some firms that have established their operations in the rural areas including industrial operations, e.g., the car assemblies outside Nairobi, ship building and repairs outside Mombasa, paper factory in Webuye and many agriculture related industries that are flooding the rural 
areas, it's hard to justify this dependence school of thought. And now that the government has taken the district level development projects approach, it is more likely that this emigration trend will dwindle.

since most of the emigrants have been of ages 20-30 and educated, it can also be argued that these people had not been very productive in the rural areas previously due to their schooling and lack of resources to use in production. Consequentiy they don't represent a loss at the present except for a future opportunity which could equally represent a future opportunity in town without guarantees. Now that MNCs have infiltrated the rural areas, they are more likely to tap this resource for a better use in rural development.

Another argument forwarded in favor of rural/urban migration has been leveled on the basis of land subdivision. According to LDC land tenure systems, the land belongs to the family and has to be subdivided into smaller pieces in every generation. As the size decreases, so are the economies of scale as well as the impossibilities of using various kinds of technologies. This means low productivity per worker and thus low income. The emigration trend is therefore a kind of safety valve to allow land pressure escape to avoid the multhusian kinds of population hazards. Thus, the fewer the workers in the rural areas, given a certain income (which might even increase due to 
economies of scale and other technological applications possible) the average per capita income in the rural areas will rise. With higher incomes, economics theory predicts high savings and therefore high investments that break the development bottlenecks inherent in rural areas. Together with the MNC supplemental assistances, labor emigration from the rural areas might turn out to be a plus to rural development.

However, some regions of Kenya are under-populated and need more labor to break through the poverty circle. Hence emigration from these areas would be disastrous. One of the remedies would be government initiatives to encourage economic opportunities to harness this labor flow. The MNCs would be another alternative as has been the case of the Mwea Tabere irrigation scheme financed by the government as well as international firms and organizations providing financial and technical assistance that has transformed a previously poor and depopulated region to an enviable resettled agricultural land.

It is with this background that the government policy makers and politicians should analyze the possibilities of screening and using MNCs to curb or promote rural/urban migration in order to develop the rural areas. 


\section{Rural Development}

One of the fundamental issues of development involves income distribution between individuals as well as between regions. Whereas in most LDCs, the rural sector always lags behind national development, the important factor to be noted is what steps are being taken to improve the situation. Initially, we should note that most of the rural sector is agricultural as opposed to the urban sector which is usually industrial. Here we deal with agriculture in terms of rural development but save its full analysis for a later section.

Thus generally speaking, any step taken to develop the agricultural sector will directly or indirectly affect the development of the rural sector. Hence as we shall see, a firm like Brooke Bond (a British multinational firm producing tea) gets credit for its promotion of agriculture in the rural areas. Thus in the 1950 s Brooke Bond built four new factories in the rural areas and in the 1960 s three more were built (Swainson 1980:251). The consequence was a source of income to the rural inhabitants both through the selling of their output as well as direct employment in the factory.

Another industry with significant contribution to the rural development has been the textile industry. For exanple, Kicomi (Kisumu Cotton Mills) has encouraged the growth of cotton around kisumu and the whole lake basin 
region as well as other rural regions of the country since cotton is cheap to transport. Rivatex (Rift Valley Textile) is another textile corporation that has promoted wool production in the Rift valley region as well as the rest of the country. Other textiles include Yuken (Yugoslavia-Kenya) textiles and KTM (Kenya Torrey Mills) textiles from Japan. All these corporations, even if they located their industries in fast growing small urban centers, have nonetheless promoted the adjacent rural areas through backward linkages in terms of agriculture and employment and forward linkages in terms of retail shops, product availability at cheap prices, contributions to local institutions such as schools, clinics and other rural projects.

Many more corporations are involved with agricultural development including Calpak (now Del Monte) in fruits, Bata Shoe Company in wattle trees and skins, uplands in bacon, Kenchic in chicken, etc. All these, in spite of their negative impacts have also striven to improve the standards of living in rural areas. The most detrimental factor being their mode of technology. And as it is typical with most foreign firms, their technologies are usually resource saving. As Hicksian technical progress definition specifies that technology could be neutral, labor saving or capital saving. It is further added that all technical progress reduces the amount of labor or capital to produce 
the same amount of output (Salvatore 1983:153). Hence we can conclude that the more technical the MNC operations are, the lesser the resources it will use within the country and therefore the lesser will be its contributions to national economic development. This means holding its forward linkages constant.

It is with this view that the Bata industry has been blamed for using imported resources and yet selling almost all of its products in Kenya.

One more significant developmental strategy in the rural areas has been contract farming. This is a mode of farming whereby the poor peasantry without initial capital except land would contract with the MNC through a state organization to receive seeds, machinery, technical advice, transport facilities, etc., in return for selling the crop to the assisting MNC which will deduct the expenses from the revenue. The most notable have been the tea and sugar agri-business. A study by Hansen and Marcussen (Review of African Political Economy \#23, 1982:9) has uncovered the means through which the peasantry have defied the dependence model and proved that international capital could be a means of emancipation and not emiserization. Accordingly out of the $\$ 200$ million revenue from tea exports, $40 \%$ stems from small holder production. Annual payments to farmers has been therefore $\$ 60$ million, i.e., K.Sh 450 with a rough 
estimate of K.Sh 4000 average income to contract farmers. This represents approximately $\$ 400$ which is twice the national average income per capita.

The same procedure is practiced in the sugar industry with the main MNCs being the Booker McConnell Agricultural firm from Britain and its subsidiary Fletcher and stewart Company. From this study, the authors conclude that contract farmers are economically better off with better housing, more consumption goods and higher possibilities of educating their children. 


\section{CHAPTER $V$ \\ IDEOLOGICALLY RELATED ISSUES}

Educational Ideology

Education is a very significant social factor in determining economic development. Indeed the basic structural ideology of development is intrinsically reflected in the education system in Kenya. So much that one of the major debates in the current development plan is to restructure the whole education system from primary to university level. The backward linkage that exists between the industrial echelon and the educational quarters has previously been that of offering jobs to the highly educated rather than the highly qualified. Thus, the level of education determines the level of the bid for a job opportunity. This bidding level in turn influences the student's false expectations and wrong decisions. We saw earlier how the education system inherited from the colonial system was carried on through the years even if its purpose had long been served. This extension in some sense can be connected to the issue at hand, i.e., the MNC effects.

As much as the colonial administrative demands were imposed on the education system to train administrators, so have been the MNCs' demand for corporate branch managers, 
accountants, secretaries, etc. However, the MNC's positions available are so few relative to the population that expects to join the MNC work force. Partial blame still holds on the government's planning but further investigations as we saw earlier point out that it is the MNCs that offer very excessive salaries, prestigious positions and luxurious benefits. The power of these amenities happen to outweigh the students' alternative decisions in terms of self employment. With sophisticated technologies of automation, the pride of working for an IBM and the exotic ties that can be made out are so compelling in decision making. And as Appendix 9 can show, the incomes of the skilled business owners are higher than those unskilled. Hence the rationale that unemployment after joining the corporation is not severe because the unemployed can start their own operations. This is a positive contribution by the MNCs but is not a solution.

It is therefore worth considering the possibilities of a diversified education system that is geared towards the multiplicity of employment opportunities such as technical, handcraft, agriculture, commerce and many more related fields that would enable a student to be self employed. The corporations can contribute in this field by entering into operations that require the related skills. Thus, not only would they be able to absorb some of the labor force but will also influence local initiative into such 
ventures. For example, baskets in Kenya were made for personal uses and very little commerce was involved on a very short extent. When a foreign firm from uganda moved into this field to produce baskets and sell them back in its home country, a group of kenyan entrepreneurs came together and organized the unemployed (mostly women) to form a production association of making baskets. Today, polytechnic schools have mushroomed all over the country based on the idea of handcraft employment of which basket making is one of the booming ventures. Baskets are sold both at home and abroad as far as the U.S. and Europe.

Another form of contribution that MNCs could avail to the education system is by apprentice or formal training of their employees. Earlier on we saw firms like kenya Breweries as being an example of this contribution. The case of General Motors is also worth noting. GM's training programme in kenya is comprehensive but flexible, ranging from straight on-the-job instruction and close supervision to perhaps scholarship academic courses at GM's private college at Flint in Michigan. There are also classroom systems developed by the corporation over many years modified where necessary for local application. In addition, a selected supervisory staff are sent overseas for further specialization training. Dealers and their employees have the opportunity to progress their own business through formal courses, seminars, and workshops at the plant 
training center in merchandising and general commercial subjects as well as vehicle maintenance and service techniques (Inside Kenya Today, \#52, June 1981:34).

\section{Political Ideology}

Carrying our analysis from Chapter I we can observe that the MNCs influence on Kenyan politics is very significant. Since the political factor is very important in any economic analysis, we shall need to note an overview of this factor. The three items to be considered are the general national ideology, internal politics and the international relations.

Generally, Kenya is a democratic government which believes in an elected parliament, the independent judiciary system and maintenance of law and order. This is essentially a Western oriented ideology in that within it is the enshrinement of a free enterprise system. However, unlike the U.S. system, the Kenyan system involves a planned economy through which the government pinpoints the target economic projects to be implemented. In some other projects, the government singularly or jointly works on particular projects to later on run them or hand them to private enterprises.

The MNC has played a significant role in the nurture of this ideology. Thus, after Independence, most of the big British conglomerates such as Lonrho, Bauman, Mackenzie 
Delgety, etc., were so diversified product wise and international wise that there grew a need to monitor their operations in the country. On the other hand, their immense power couldn't allow complete government control. Hence, an indicative plan which could use inducements towards certain targets became the appropriate alternative. This meant free enterprise in a planned economy.

other factors too contributed to this system. Some were, in fact, the creations of the MNC. We have already noted how the MNC hiring policies created an elite bourgeoisie. Because of the wealth they have obtained through directorships of various MNCs and thereby made huge investments as is the case for the karumes, Njonjos, the Blocks, etc., these peoples' political careers rest on the existence of the free enterprise system. Hence, the internal politics surrounds the issues of benefits and costs of MNCs. Hence such events as the boardroom crisis which we noted earlier (Swainson 1980:280) whereby the Kenyan Director who is a politician had not only stood up for the company's activities in the country but also defended it at its headquarters against the British government's wish to regulate its foreign activities on the basis of the free enterprise system. It is therefore worth noting that the MNCs have had a significant role in shaping the internal political ideology of Kenya. 
Likewise, the MNCs have had some effect on kenya's international politics. Thus, with the neighbors, this has come about through the supply of manufactured commodities from MNCs as we noted earlier in the thesis. We saw how Kenya exported more goods to its neighbors than it imported (Leys \& Robson 1965:233-235). We then noted the collapse of the East African community as being due to this trade inequality. The MNC therefore had a role to play. On the other hand, Kenya's highest trading partner is the U.K. (see Appendix 6). It also happens that most of the MNCs in kenya are of British origin. In spite of the historical fact that Britain was a colonial mother to kenya, the British MNCs too have contributed a lot to the maintenance of this current ideology.

Most significant is its position as a non-aligned country welcoming both investments from the west and East, North and South and even from military-run governments. The inherent rationale is that of free enterprise which we have noted to be impressed by MNCs. 


\section{SUMMARY}

We have seen the economic problems facing a developing nation that relates the impact of the Multinational corporations. In the first chapter we reviewed various economic theories and concepts as they relate to development of the Kenyan economy in general. We found that kenya was economically better off than its neighboring countries and that without protectionism, Kenya would have benefited even more.

In trying to examine how the Kenyan economy has managed to be in that position in Chapter II, we found the issue of the Multinational Corporations which had existed there before independence. These MNCs have virtually controlled most of the economy but also posed some serious problems. These problems were then examined in individual sections such as were labor related issues in chapter III, rural development issues in Chapter IV and ideologically related issues in chapter $V$. These were considered to be the leading issues that the MNCs have had an impact on both positive and negative.

Since this paper was meant to investigate most of the charges leveled on MNCs, a lot of the effort was put into bringing to the attention of some of the positive effects of MNCs that are often ignored. We found several of these 
contributions in terms of labor employment, technological and managerial skills transfer, creation of urban centers in rural areas as well as shaping the ideological view points towards the economic mechanisms of efficiency as guided by the goal of profitability.

These effects were most reflected in the years from 1960 to 1980. The 1960 s actually reflect kenya as being closely at the same level with its neighbors (Appendices 14, 15 and 16). However, the 1970s reflect Kenya's new policy of encouraging multinational corporations (Appendices 8 and 9). The consequent results reflect kenya as having changed faster than its neighbors (Appendices 17, 18 and 19). Such effects therefore were found to have a positive image of the multinational corporations on Kenya. 
CONCLUSION

Based on the facts revealed, and under the Economic Conditions prevailing, Kenya's problem with MNCs should not focus on issues of whether MNCs are acceptable in the country but how to co-exist with them. Given the current elites' position, who indeed are the ones against MNCs, the competitive edge posed by MNCs might never be replaced and efficiency might be a dream. It is therefore on this basis that I set my recommendation, i.e., how to co-exist and how to be efficient in decision making. 
RECOMMENDATIONS

One of the major problems in all the issues we discussed was the transfer of inappropriate technologies. The criteria most cited was that of labor saving technologies which the MNCs are very fond of. If we have to take a micro point of view, labor saving technologies create unemployment problems. However, on a macro basis, we need to evaluate the overall effect of such a technology on the economy. By this I include the effect of revenues created such as direct corporate income tax, employee taxes, skills transferred (technical and managerial), foreign exchange savings, backward and forward linkages generated and a chain of other benefits. These are to be balanced with the burden of technology on the economy. Given such information, a labor saving technology might turn out to be a very essential technology to the economy.

For example, we found out that Calpak's technology was labor saving in terms of farming operations. We also found that the technology was aimed at producing high quality fruits for international marketing. Given that these fruits are exported to various parts of the world, there is a whole set of multiplier effects on factors such as transportation, workers, administrative agencies, income taxes, etc., that have been generated to consider. In this case, 
this venture might turn out to be encouraging. As a policy tool therefore, a cost/benefit analysis will be very essential to determine the acceptability of any given technology. The major criteria that I suggest is the contribution to the financial status of the economy. Preserving jobs that become a burden to the economy is not any better than burdening the economy with unemployment. Hence, special interest criteria that sway away from the positive financial cost/benefit balance should be put on the second best principle, i.e., other factors should only be considered when the cost/benefit analysis cannot work.

Another problem we discovered was the tendency of MNCs to shift towards manufacturing industrial production than agricultural. The issue is that most of the kenyan economy is dominated by agriculture and therefore in order to nurture the economy foreign enterprises are supposed to indulge themselves in agricultural related activities of which most do not. Thus, if MNCs are not involved in such a large sector of the economy then they are not after promoting development.

Whereas a large sector of the national economy is very important in development strategy, it is equally questionable about the appropriateness of emphasis on such a sector. Put objectively, the primary purpose of any business is to earn revenue in the most optimum way. Naturally therefore, if foreign enterprises are more interested in 
the industrial sector, then it is most likely that this sector is more attractive. It is therefore upon government policy makers to use such tendencies as measuring scales for the appropriateness of any development strategy. Given that the law of demand and supply operates, and allowing for some corrections in the assumptions behind the theory, it would be more useful to employ a cost/benefit analysis of the contributions of each sector in the economy before putting any emphasis on a particular sector. For example, we all know the importance of food for any nation. But using a hypothetical case, supposing we use the comparative theory approach that we analyzed in chapter I. The cost of producing corn is several times lower in the United states than it is in Kenya due to large scale mechanization. On the other hand, the cost of assembling watches, electronic equipment and most other repetitive jobs is lower in kenya than in the U.S. due to the high supply of cheap labor. From the Kenyan perspective, it should be worth the effort of attracting an MNC that introduces such technical operations whose man/hour output will more than compensate for the man/hour output of foods that can be imported cheaply. Thus, if parts could be imported and assembled products such as watches exported cheaply, then the development strategy should lean towards such a sector.

We also noted the issue of stiffening competition. In the study of capitalism, competition is viewed as a healthy 
sign of economic growth. It is the most efficient means of resource allocation. However, in the real world, perfect competition is only hypothetical. We have monopolies, oligopolies with all sorts of product differentiation, predatory operations and many kinds of interventions. Hence, if a national economy or strategic operations are left in the hands of foreign firms alone, the results might be detrimental to the economy. Hence, policy makers should attempt to pave means through which national firms are protected from unfair competition. The criteria of unfairness will include parameters such as the required capacity for efficient operation, i.e., a local firm should be protected up to a point where its size is at the optimum output. Another parameter would be where a foreign firm's marginal cost is above the price charged. In such a case, investigations should be made in case there are predatory intentions. Other parameters should be used to evaluate particular areas that need protection (except for those that are sensitive to the national security whereby secrecy overrules efficiency).

However, the problem is to determine the accuracy of such parameters. For example, what is the optimum level of output for a particular firm in kenya whose counterpart is located in the United States? Both firms have a variety of differences in terms of inputs and may require different procedures based on costs. But as a policy maker, it is 
worth using the best judgement, such as the industry's average cost internationally with allowances for Kenyan positive and negative conditions. Thus, refusing entrance of foreign firms just because of fear of competition in its entirety is detrimental to the nation's economic development. On the other hand, open door policies without consideration of factors that stifle competition is as detrimental. Overall, the criteria should be based on longrange benefits over costs. After all, if the primary goal is development, it shouldn't matter who brings about that development. As long as the means are fair and the long run results are impressive, policy makers should develop no bias of whom to rubber stamp for the initiation or processing of any particular economic project.

The costs of evaluating the basis of selection is also very critical. The analysis of benefits and costs should only go as far as the future expected payoffs warranty. As a rule of thumb, however, where the balance evens out, the local entrepreneurs should be given pre-emptive opportunity.

The problem of urban/rural development is another issue whose MNC's impact has had a significant effect. On one hand, the MNCs have tended to mushroom their operations in urban areas and therefore facilitated economies of scale on which other economic entities could be established. On the other hand, the Marxists would view this approach as 
being static and not dynamic. Thus, it has been argued that the urban areas act as satellite centers which attract development opportunities away from the rural areas (periphery) and therefore bring about unfairly unbalanced growth. Since most MNCs are located in urban areas, they are therefore equally guilty of creating such an economic environment. With certain qualifications therefore the MNCs have contributed to regional disparities such as exist between Nairobi, Mombasa, Nakuru, Kisumu, etc, , and other urban areas as well as between all large urban areas and rural areas.

Based on the possible negative impact that may ensue, it is therefore essential that policy makers objectively formulate viable policies that can promote both regions in the most efficient but productive way. In any case, the long run effects should be put in perspective. For example, some firms which are footloose have been found in Nairobi. Given such a characteristic firm, policy makers would be doing the nation a service if they pushed them to the rural areas and allowed more firms into Nairobi if those firms are attached to operations in Nairobi through backward or forward linkages. Forcing footloose firms to locate somewhere else is cheaper since the costs of crowding in Nairobi may outpace the gains. And with new growing urban centers distributed all over the country, the marginal costs of developing a particular rural project may fall 
due to economies of scale to be obtained from the new town. For example, costs of electric power, telephone lines, water pipelines, roads, etc., would be shared as we saw in the case of Webuye Paper Mills that has transformed a small township with low economic potential to a very strategic economic satellite.

Related to the above is the land tenure system. The rural areas will not develop fast without effective policies governing land use and tenancy. In Chapter II we suggested a policy of penalties for under-utilization of land and incentives for its efficient use. The scale of land is also as important. In order to use land efficiently, the economic laws that govern other commercial sectors should apply. Whereas subsistence farming has done a great service to the poor peasants, there is need to transform this method into more productive ways so as to break through the poverty barriers. Therefore, the size of the farm should suit the kind of farming. For example, it would be uneconomical for a five acre farm to support five cows that depend on grass alone for food without supplemental intensive care. And the excessively large farms should be subdivided into smaller economical sizes.

The policy makers should therefore educate peasant farmers that land subdivision within the family drains out the economies of scale unless scientifically managed. Large scale farmers should be aware of benefits from 
optimum land use so as to use it intensively as small scale farmers or else some portions of it. As any commercial enterprise, the main objective should be profitability of any venture that a farmer goes into. With such a tangible incentive, a farmer is more likely to efficiently use resources at his disposal. And given that MNCs are encouraged to locate their operations in these rural areas, economies of scale are likely to benefit both parties. Not only would MNCs provide markets for farm products but also the starting capital, contribution to infrastructure and the shaping of attitudes towards efficiency and commercialization of farm products. With these, specialization into a particular product will be possible. The landless can therefore find other occupations that are related to links between MNC and farming operations.

In sum therefore, policy makers should discourage MNC locations into major urban centers unless absolutely necessary. This way, the MNC operations in the rural regions would help foster the growth of other rural economic potentials. Incentives should be used to encourage these MNCs spread effects as long as the costs do not outweigh the benefits. Indeed, like any other resource input, an MNC should be evaluated as any capital item to be injected into the economy.

In Chapter II we found out that foreign political ideologies infested through MNCs have complicated economic 
operations into political power fighting scenarios. Indeed, the major economic problem, as we mentioned earlier, in LDCs has been political. Choices of which MNCs to welcome are likelỳ to be biased, so as to the criteria used. It is therefore fundamental that the political system is shaped appreciably before most of the cohesive beneficial economic policies can be upheld. Whereas, as an economist, I can't dwell deeply in political theorizing, it is equally essential that economic policies govern political policies towards economic development. Thus, a political decision that chooses an MNC with high costs relative to the other without further objective and verifiable qualifications should be objected. Politicians should avoid rule of thumb policies when dealing with economic issues. For example, unemployment cannot just be solved overnight by a "back-tothe-land" policy. Planning, evaluation and practicability are vital. It is the long run impact of the MNC that should be considered, not the current political ties it has.

Tied into this issue is the choice based on the MNC originality. Economic issues should minimize political and ideological boundaries. Thus, the choice of whether to choose a firm from a capitalist of socialist state should be governed by the firm's overall impact. Once again, the question of efficiency and utilization of local resources arise. Several economic criterias should be used, such as 
where it wants to locate, probable linkages it will provide, technological breakthroughs, availability of local inputs and serviceability, as well as likelihood of convertibility to local ownership.

It is true that the world is becoming smaller and coping up with the international environment should be the basis of any policy making - with the current MNCs phenomena, coexistence is a given fact for economic development, the issue is how to optimize the situation. 


\section{BIBLIOGRAPHY}

Bartiz, F. L. R., "Trade Theory, Distribution of Income, and Immigration", The American Economic Review, May 1983.

Bhagwati, J. N., Brecher, R.A., and Hatla,T., "The Generalised Theory of Transfers and Welfare: Bilateral Transfers in a Multilateral World". The American Economic Review, September 1983.

Blood, W. J., "Business Conditions in East Africa", Management Looks at Africa, 1966 (Library of Congress Card Number 66-24179).

Caves, R. E. "Multinationalenterprise and Economic Analysis." Cambridge University Press (1982).

Clark, P. G., Development Planning in East Africa." East African Studies 21 (Kenya Litho Ltd., 1965).

Colman, D. and Nixson, F. "Economics of Change in Less Developed Countries." Halsted Press Book (1978).

Eiteman, D. K. and stonehill, A. I., "Multinational Business Finance", Third Edition (Addison-Wesley Publishing Co., 1982).

Frank, I. "Foreign Enterprises in Developing Countries." John Hopkins University Press (1981).

Forrester, M. W., "Social Prerequisites for Economic Development." Kenya Today (N.V.D. Reidel, Dordrecht, 1962).

Gurley, J. G., "The Triumph of Capitalism". Challengers of Capitalism (W. W. Norton \& Co. 1979).

Killick, T., "Past and Future Research on the East African Economies", Eastern Africa Economic Review December 1976 , volume 8 , Number 1 .

"Strengthening Kenya's Development strategy: opportunities, Constraints", Eastern Africa Economic Review, Dec. 76 , Vol. 8 , \#2. 
Kindleberger, C. P., and Herrick,B. "Economic Development." McGraw-hill Book Company (1983).

Langdon, S. W., Multinational Corporations in the Political Economy of Kenya, (St. Martin's Press, N.Y., 1981).

Leys, Collin, "Foreign Capital", Underdevelopment in Kenya University of California Press 1974).

Leys, C. and Robson, P., "Appendix", Federation in East Africa (Oxford University Press 1965).

Marvel, H. P. and Ray, E. J., "The Kennedy Round: Evidence on the Regulation of International Trade in the United States", The American Economic Review, March 1983.

Morris, P. and Somerset, A., The African Entrepreneur (African Publishing Corporation, 1971).

Mutharika, B. W. T., Toward Multinational Economic Cooperation in Africa (Praeger Publishers, 1972).

Nehrt, I. C., "The political climate for private foreign investments", (Praeger Publishers, 1970).

Ogendo, R. B., Industrial Geography of Kenya (East African Publishing House, 1972).

Oser, J., "Rich and Poor Countries," Promoting Economic Development (Northwest University Press 1967).

Oucho, D. J. and Makras, M. S., "Migration, Transfers and rural developement - A case study of Kenya" (East African Literature Bureau, 1984).

Pearson, D. S., "Industrial Development in East Africa." Studies in African Economics 2, (Oxford University Press, 1969).

Salvatore, D. "International Economics." Macmillan Publishing Co., Inc. (1983).

Seidman, A., "An Economics textbook for Africa", Third Edition (Methuen London and New York, 1982).

Swainson, N., "The State and Economy in Kenya." The Development of Corporate Capitalism in Kenya 1918-1977, (University of California Press, 1980). 
Todaro, M. P., Economic Development in the Third World. Second Edition, (Longman 1981).

Todaro, M. P., struggle for Economic Development (Readings). (Longman 1983).

Vernon, R. and Wells, L. T., "Moving Goods Across National Borders". Economic Environmetn of International Business (Prentice Hall, Inc. 1981).

Zajadacz, P., Studies in Production and Trade in East Africa (Weltforum Verlag. Munchen 1970).

Zwanenberg, R. M. A. and King, A., "East African and Economic Federation", An Economic History of Kenya and Uganda 1800-1970 (Humanities Press 1975).

"Development Plan 1984-1988." Government Printers, Nairobi (1983).

"Kenya, Foreign Investment in a Developing Economy." A Business International Research Report, 1980 (Library of Congress Card Number 80-81285).

"Kenya, Progress and Problems." British Information Services, 1960.

"Kenya, official Handbook." Government of the Republic of Kenya (1983).

"Strengthening Kenya's Development Strategy: Opportunities, Constraints." Eastern Africa Economic Review, Dec. 76, Vol. 8, \#2.

"The Economic Development of Kenya." International Bank for Reconstruction and Development. (Johns Hopkins Press, 1963).

Kenya Today (Number 52 -June 1981). Stellascope Printing Company, Nairobi (1981). 
Weekly Review News Magazines, Kenya, Stelescope Printers

(NRB) Publications: September 23, 1983

October 7,1983

November 11, 1983

November 11, 1983

December 16,1983

March 2, 1984

June 15, 1984

June 22,1984

August 19, 1984 


\section{APPENDIX 1}

\section{Principal Exports from Kenya 1937}

Coffee

Sisal

Tea

Gold

Maize

Hides

Sodium Carbonate

Skins
18.88

17.38

12.08

10.78

5.18

5.08

5.08

3.08

SOURCE: Overseas Economic Survey, Swainson, p. 46 (The Development of Corporate Capitalism in Kenya). 


\section{APPENDIX 2}

\section{$\frac{\text { Kenya's Major Trade Partners }}{\text { (\$ millions) }}$ \\ (Excluding EAC Partners)}

\begin{tabular}{|c|c|c|c|c|}
\hline Imports & 1976 & 1977 & 1978 & $\begin{array}{c}8 \text { Increase } \\
77 / 78 \\
\end{array}$ \\
\hline EEC & 391 & 577 & 912 & 58.2 \\
\hline U.K. & 185 & 165 & 394 & 138.8 \\
\hline Germany & 98 & 146 & 237 & 62.7 \\
\hline Japan & 108 & 133 & 183 & 37.7 \\
\hline Iran & 164 & 115 & 121 & 5.7 \\
\hline U.S. & 57 & 76 & 111 & 45.7 \\
\hline France & 31 & 66 & 83 & 25.7 \\
\hline Italy & 21 & 55 & 90 & 63.2 \\
\hline
\end{tabular}

Exports

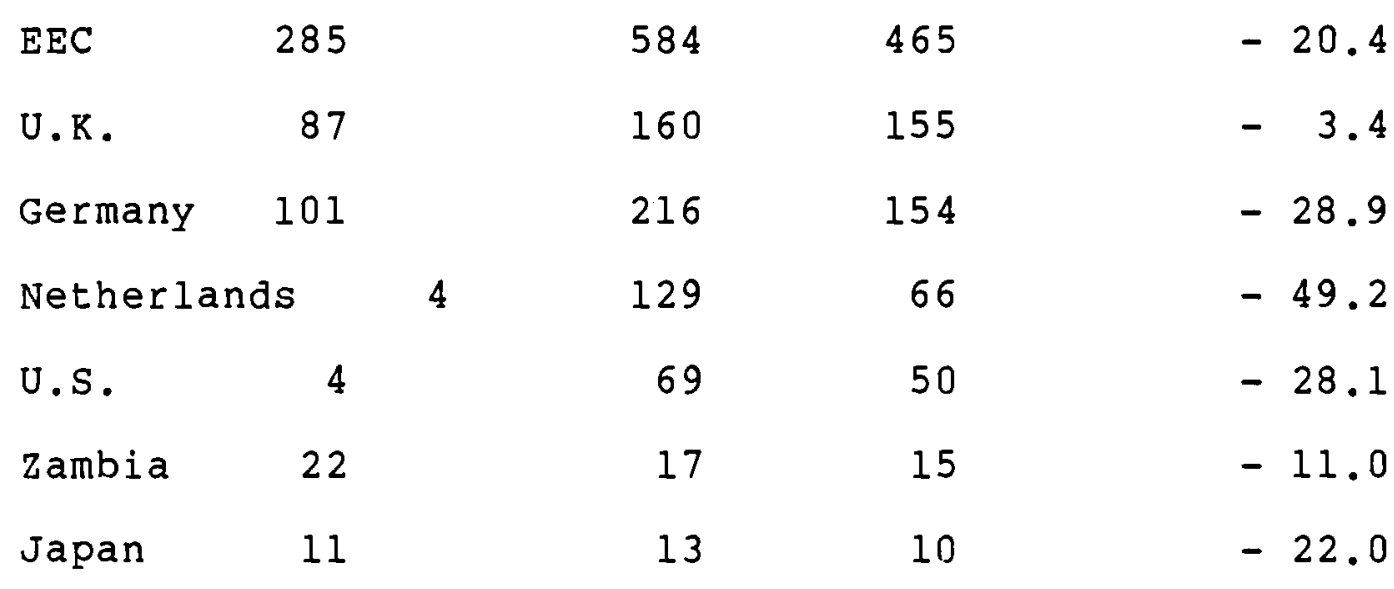

SOURCE: Bl and Foreign Economic Trends Report, U. S. Embassy, Nairobi (Foreign Investment in a Developing Economy, Kenya). 


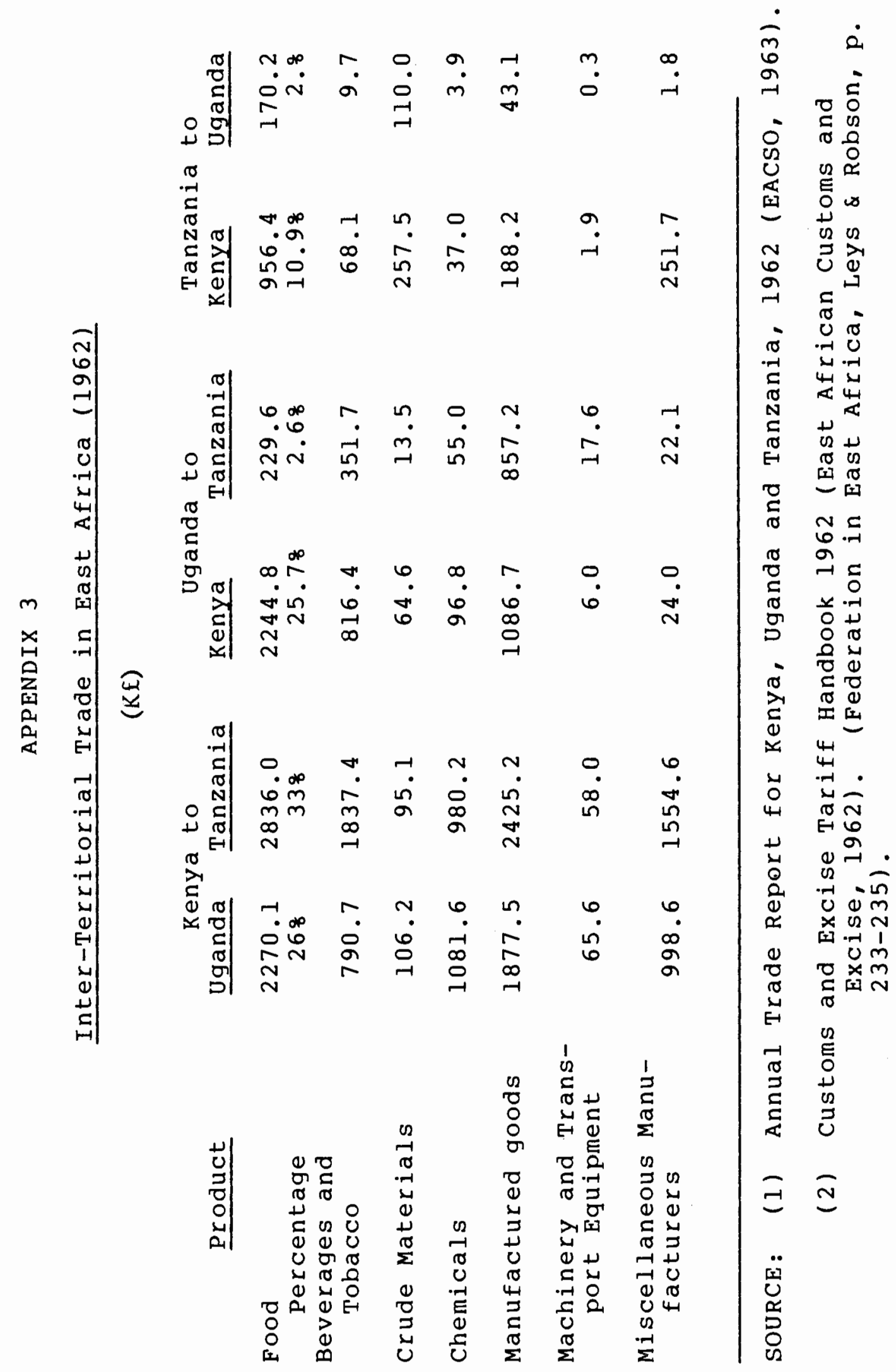




\author{
APPENDIX 4 \\ Visible Balance of Inter-Country Trade \\ (KE millions)
}

$\begin{array}{lccc} & \text { Kenya } & \text { Uganda } & \text { Tanzania } \\ 1959 & +6.8 & -13.8 & -5.52 \\ 1961 & +8.9 & -.58 & -8.37 \\ 1963 & +10.6 & -1.69 & -8.93\end{array}$

SOURCE: EConomic History of Kenya and Uganda 1800-1970 by Zwananberg and King, p. 244. 


\section{APPENDIX 5}

Expansion of Inter-Territorial Trade in E. Africa
(KE millions)

\section{Kenya}

1944

1948

1951

1954

1957

1960

1963

1966
Uganda

1.98

3.19

4. 31

7.54

5.32

6.69

8.24

10.45
Tanzania

0.66

0.83

1.15

1.04

2.02

2.33

2.43

4.65
Total

3.73

5.95

9.18

11.49

18.77

22.79

31.47

44.00

SOURCE: Van Zwanenberg and King, "East Africa and Economic Federation: The East African Common Market" (An Economic History of Kenya and Uganda 1800-1970). 


\title{
APPENDIX 6
}

\begin{abstract}
Differential Pricing of Agricultural Products Average Unit Values in External and Inter-Territorial Exports in East Africa, 1962
\end{abstract}

\section{Commodity}

Beef and Veal

Bacon, Ham and Pork

Ahee

Butter

Cheese

Biscuits overseas

$$
7.8
$$

15.1

15.8

11.5

13.0

8.8

17.2

14.6

10.2

104

SOURCE: D. G. R. Belshaw, Agricultural Production and Trade in the East African Common Market (Federation in East Africa by Leys \& Robson, p. 84). 


\section{APPENDIX 7 \\ Estimated Book Value of Foreign Investments in Kenya in 1972}

\section{Country}

United Kingdom

United States

Germany

France

Japan

TOTAL $\underline{\text { KE M }}$

87

26

6

5

1

130
$\&$ of Total

67

20

5

4

2

100

Source: Swainson, p. 215. 


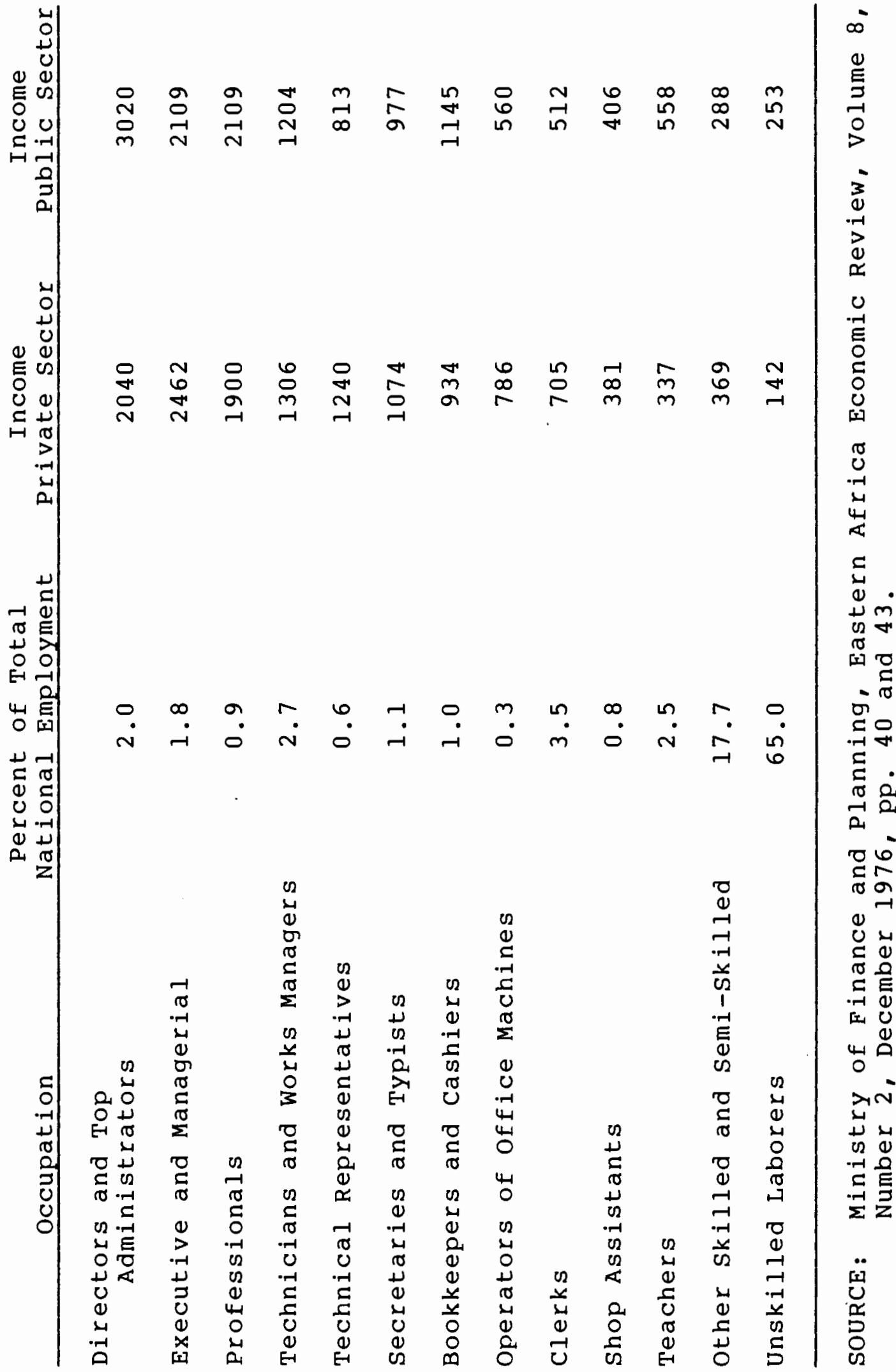




\section{APPENDIX 9}

Basic Firms in Kenya by Ownership and Employment Leve1 1974-1975

Paper Products

Printing and Publishing

Basic Chemicals

Soap

$$
\begin{aligned}
& 1 * \\
& 3
\end{aligned}
$$

Miscellaneous Chemicals

Non-metal Mineral Products

* Means a multinational corporation.

SOURCE: Ministry of Labor, Eastern Africa Economic Review, volume 8, Number 2, December 1976, p. 49. 


\section{APPENDIX 10}

Percentage of Gross Product By Foreign Ownership

\begin{tabular}{lcc} 
Mining and Quarrying & 1967 & $\frac{1972}{818}$ \\
Manufacturing and Repairs & 938 & 818 \\
Building and Construction & 718 & 638 \\
\hline
\end{tabular}

Source: Census of Industrial Production for 1907-72, Central Bureau of statistics, Treasury (Swainson, p. 241-242). 
APPENDIX 11

Number of Private Companies

Forming in Kenya Between 1955-1973

\begin{tabular}{|c|c|c|c|c|}
\hline Year & European & Asian & African 8 & Mixed $q$ \\
\hline 1955 & 70 & 28 & -- & 6 \\
\hline 1960 & 50 & 42 & 4 & 4 \\
\hline 1965 & 28 & 34 & 25 & 12 \\
\hline 1970 & 13 & 37 & 30 & 20 \\
\hline 1973 & 15 & 24 & 46 & 15 \\
\hline
\end{tabular}

Source: Annual returns of the Registrar General, summary of Yearly Statistics (Swainson, p. 195). 

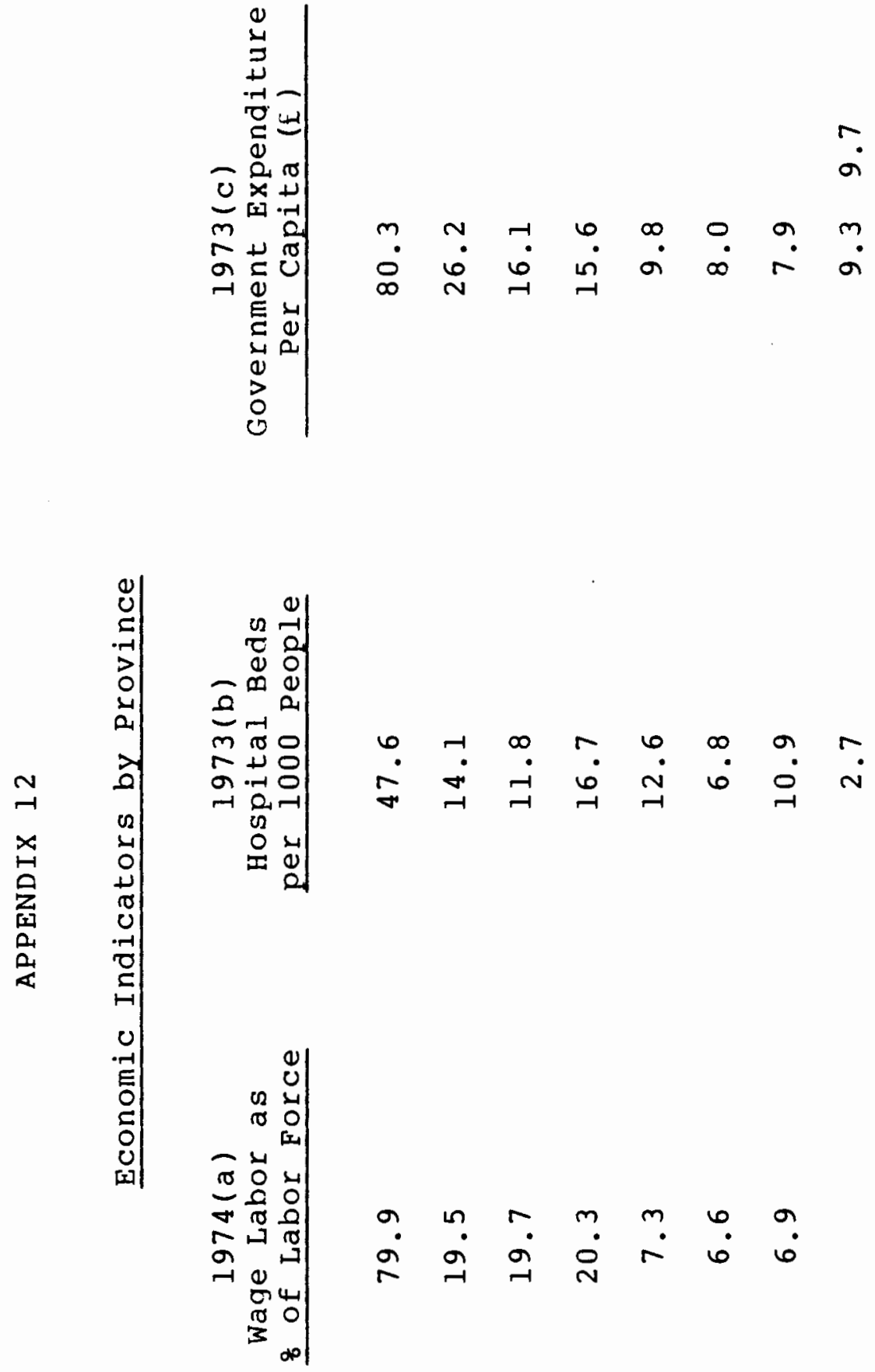

$\begin{array}{llllllll}0 & -1 & \infty & \sim & 0 & \infty & 0 & N \\ \sim & \dot{r} & \dot{H} & 0 & \dot{1} & 0 & \dot{0} & \dot{1}\end{array}$

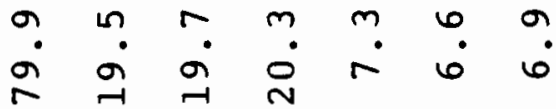

3
1
01
0
-1
$=-1$

국

0
0
0
0
0
0
0
0
0

$\underline{U}$

i)

in $\infty$

o

멍

$\pi$

03

$+1$

- $\rightarrow$ d

$\underset{\sigma}{1}$

$+0$

呚

$\approx \stackrel{9}{0}$

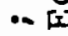

$+$

$\begin{array}{ll}0 & 0 \\ -1 & 0\end{array}$

$\perp \cdot$

Q 4

足出

元

0

$+$

O

$+E$

$\pi$

$\vec{U} \cdot=$

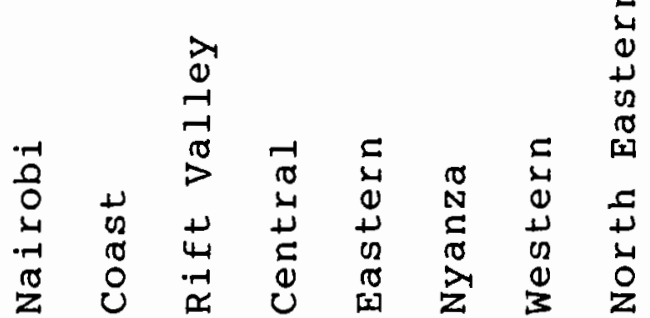




\section{Previous Occupation of Market Businessmen}

Occuption Before Taking Profit Under Profit Up Business $300 /-$ p.m. $300 /-$ D.m. + All

\begin{tabular}{|c|c|c|c|}
\hline Farming & 178 & 158 & $17 \%$ \\
\hline $\begin{array}{l}\text { Employed: } \\
\text { Unskilled } \\
\text { Skilled manual } \\
\text { Clerical, teaching } \\
\text { Army, police }\end{array}$ & $\begin{array}{r}188 \\
238 \\
158 \\
48\end{array}$ & $\begin{array}{r}108 \\
278 \\
218 \\
68\end{array}$ & $\begin{array}{r}168 \\
258 \\
178 \\
48\end{array}$ \\
\hline At school & 68 & 58 & 58 \\
\hline In detention & 18 & 18 & 18 \\
\hline Hawker or petty trader & 88 & $9 \%$ & 88 \\
\hline No occupation & 88 & 68 & 78 \\
\hline TOTAL \& & 1008 & 1008 & 1008 \\
\hline TOTAL NO. & 445 & 178 & $786 *$ \\
\hline
\end{tabular}

* Including businesses where profit could not be estimated, but excluding one market where the question on previous occupation was not asked.

Source: Morris and Somerset, p. 245. 


\section{APPENDIX 14}

World Trade in Millions (E) Exports* 1960s

Year

1964

1965

1966

1967

1968

59.28

62.63

51.87

62.16

67.12

65.54

66.35
Tanzania

$$
70.25
$$

62.93

83.90

79.11

81.10

*Trade between Kenya, Uganda and Tanzania excluded.

SOURCE: Monthly Bulletin of Statistics, Department of Economics and Social Affairs, Statistical office, United Nations, New York, 1968, pp. 118, 125 and 126. 
APPENDIX 15

World Trade in Millions (E) Imports* 1960s

Year

1964

1965

1966

1967

1968

106.51

114.84

76.53

88.95

112.23

42.90

41.29

43.80

Tanzania

43.96

50.01

64.20

65.02

76.58

*Trade between Kenya, Uganda and Tanzania excluded.

SOURCE: Monthly Bulletin of Statistics, Department of Economics and Social Affairs, Statistical office, United Nations, New York, 1968, pp. 118, 125 and 126. 
APPENDIX 16

National Income in Millions (E) Market Prices 1960s

\begin{tabular}{lccc} 
Year & Kenya & Uganda & Tanzania* \\
\hline 1959 & 215 & 149 & - \\
1960 & 226 & 152 & 173 \\
1961 & 225 & 156 & 181 \\
1962 & 244 & 157 & 186 \\
1963 & 329 & 176 & 211 \\
1964 & 352 & 195 & 226 \\
1965 & 359 & 223 & 228 \\
1966 & 410 & 243 & 252 \\
1967 & 440 & 381 & 283 \\
1968 & 478 & 328 & 293 \\
\hline
\end{tabular}

*Tanzania shillings converted into pounds.

SOURCE: Monthly Bulletin of Statistics, Department of Economics and Social Affairs, Statistical office, United Nations, New York (1968, pp. 178-179 and 1972, pp. 186 and 187). 


\section{APPENDIX 17}

World Trade in Millions (Shillings) Imports* 1970s

\begin{tabular}{lrrr} 
Year & Kenya & Uganda & Tanzania \\
\hline 1972 & 3957 & 1158 & 2956 \\
1973 & 4571 & 1139 & 3479 \\
1974 & 7679 & 1556 & 5258 \\
1975 & 7253 & 1469 & 5694 \\
1976 & 8140 & 1325 & 5421 \\
1977 & 10626 & 1992 & 6161 \\
1978 & 13223 & 1963 & 8581 \\
1979 & 12386 & 1472 & 8885 \\
1980 & 19181 & 2175 & 10046 \\
\hline
\end{tabular}

*Does not include trade between Kenya, Uganda and Tanzania.

SOURCE: Monthly Bulletin of Statistics, Department of Economics and Social Affairs, statistical office, United Nations, New York, 1985, pp. 148 and 164 . 
World Trade in Millions (Shillings) Exports* 1970s

\begin{tabular}{lccc} 
Year & Kenya & Uganda & Tanzania \\
\hline 1972 & 2654 & 2019 & 2277 \\
1973 & 3614 & 2206 & 2587 \\
1974 & 4714 & 2331 & 2861 \\
1975 & 4761 & 1977 & 2764 \\
1976 & 6901 & 3002 & 4007 \\
1977 & 9893 & 4859 & 4471 \\
1978 & 7915 & 2682 & 3669 \\
1979 & 8269 & 3246 & 4216 \\
1980 & 10314 & 2558 & 4161 \\
\hline
\end{tabular}

*Does not include trade between Kenya, Uganda and Tanzania.

SOURCE: Monthly Bulletin of Statistics, Department of Economics and Social Affairs, Statistical office, United Nations, New York, 1985, pp. 148 and 164. 


\section{APPENDIX 19}

National Income (Millions of Shillings) 1970s

\begin{tabular}{cccc} 
Year & Renya* & Uganda & Tanzania \\
\hline 1969 & 10418 & 8300 & 8271 \\
1970 & 11454 & 9400 & 9173 \\
1971 & 12707 & 1043 & 9792 \\
1972 & 14516 & - & 11270 \\
1973 & 16652 & - & 13184 \\
1974 & 20452 & - & 15644 \\
\hline
\end{tabular}

*Kenya pounds converted into shillings.

SOURCE: Monthly Bulletin of Statistics, Department of Economics and Social Affairs, Statistical office, United Nations, New York, 1977 (pp. 187 and 189. 